
BALLISTIC IMPACT OF SINGLE PARTICLES INTO GELATIN: EXPERIMENTS AND MODELING WITH APPLICATION TO TRANSDERMAL PHARMACEUTICAL DELIVERY

\author{
By \\ Rachel Ann Guha, B. Eng. \\ Ryerson University, 2007 \\ A thesis \\ presented to Ryerson University \\ in partial fulfillment of the requirements for the degree of \\ Master of Applied Science \\ In the Program of \\ Mechanical Engineering
}

Toronto, Ontario, Canada, 2009

Rachel Ann Guha 2009 C 


\section{AUTHOR'S DECLARATION}

I hereby declare that I am the sole author of this thesis

I authorize Ryerson University to lend this thesis to other institutions or individuals for the purpose of scholarly research.

I further authorize Ryerson University to reproduce this thesis by photocopying or by other means, in total or in part, at the request of other institutions or individuals for the purpose of scholarly research. 


\section{BORROWER'S PAGE}

Ryerson University requires the signatures of all persons using or photocopying this thesis.

Please sign below and give the address and date. 


\title{
ABSTRACT \\ Ballistic Impact of Single Particles into Gelatin: Experiments and Modeling with Application to Transdermal Pharmaceutical Delivery
}

\author{
Master of Applied Science, Mechanical Engineering, 2009, Rachel Guha
}

\section{School of Graduate Studies, Ryerson University}

The high speed penetration of particles into the human dermis is of interest for targeted drug delivery by transdermal powder injection. However, performing well-controlled single impact experiments with micron scale particles on dermal tissues is difficult. Therefore, the suitability of the use of a dimensionally scaled up 'model' system utilizing steel balls impacting a gelatin to simulate the perforation of micron sized gold particles into human skin was investigated. A finite element (FE) model of a 'calibration' system consisting of a $2 \mu \mathrm{m}$ gold sphere impacting the human dermis at $651 \mathrm{~m} / \mathrm{s}$ was used to extract the combinations of possible epidermal material properties which allowed an FE predicted penetration able to match measured data from an existing study in the literature. Novel scaling laws were developed to link the 'model' and 'calibration' systems, and impact experiments were performed on gelatins of various formulations to determine the formulation that produced a penetration which, when scaled, matched that of the calibration system. The resulting material properties of the gelatin were appropriately scaled and used to choose the best combination of skin material properties. In this manner, a quasi static elastic modulus of $2.25 \mathrm{MPa}$ was found for skin, in good agreement with reported values from the literature. Further experiments were performed with steel, polymethyl-methacrylate, titanium, and tungsten carbide balls impacting the gelatin, in order to determine the effects of particle size and density on penetration depth. FE simulations of both the model and calibration systems confirmed the scaling relationships and impact behavior found in these experiments. Both the FE model and the steel-gelatin experiments were able to predict the penetration trends found by other investigators in the examination of typical particles used for vaccine delivery. It can therefore be concluded that scaled up systems utilizing ballistic gelatins can be used to investigate the performance of transdermal powder injection technology. 


\section{ACKNOWLEDGEMENTS}

I would like to start by thanking my supervisor Dr. Marcello Papini for his enthusiastic guidance, great insights and perspectives, whose expertise and understanding added considerably to my graduate experience.

I owe my sincere gratitude to Devin Ostrom for his technical support during various stages of this research. Thanks are also due to my colleagues David Ciampini, Getu Hailu, Tom Burzynski, and Mahdi Takaffoli, for all the advice and the laughs.

I would also like to thank my mother, father, and sister, for their continued support and encouragement throughout these years of schooling. And to hWeez for sheer entertainment value. Also, in the memory of Dudi...

\section{Rachel Guha}




\section{TABLE OF CONTENTS}

AUTHOR'S DECLARATION
BORROWER'S PAGE.
ABSTRACT.
ACKNOWLEDGEMENTS
TABLE OF CONTENTS
LIST OF FIGURES
LIST OF TABLES
NOMENCLATURE
Chapter 1. Introduction
Chapter 2. Literature Review.

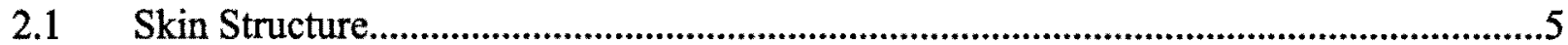

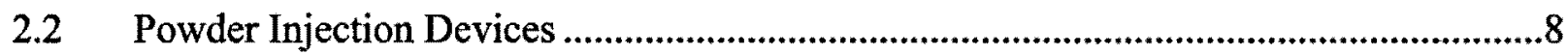

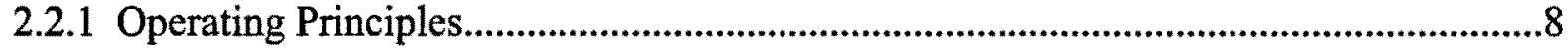

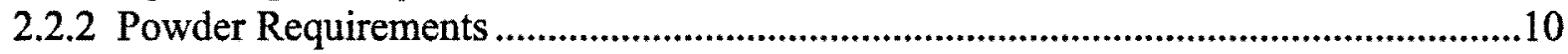

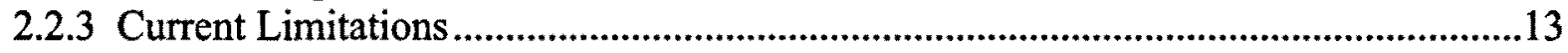

2.3 Modeling Particle Ballistics into the Skin ...................................................................15

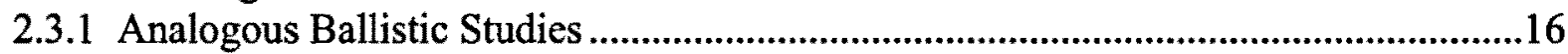

2.3.2 Measured Mechanical Properties of Skin ............................................................18

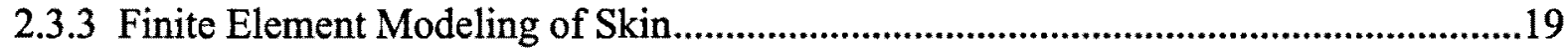

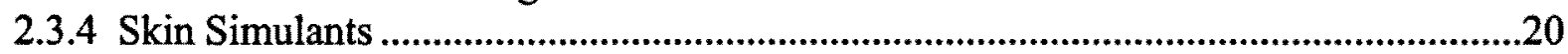

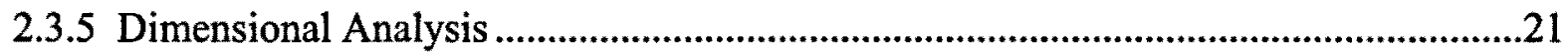

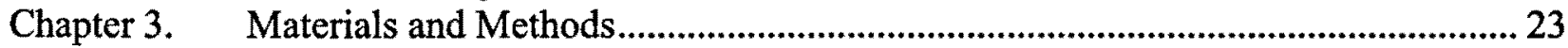

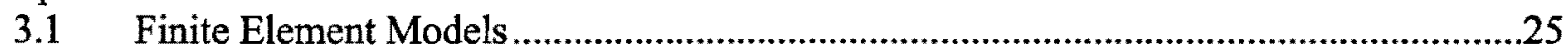

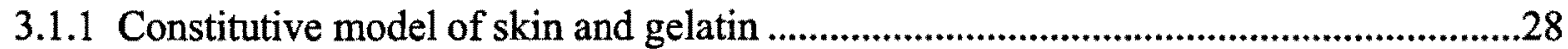

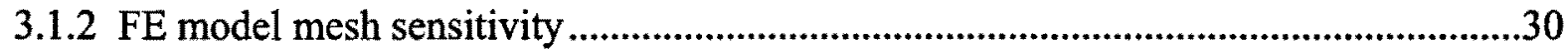

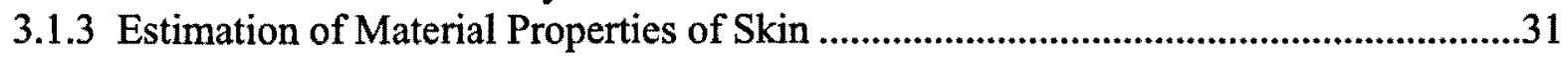

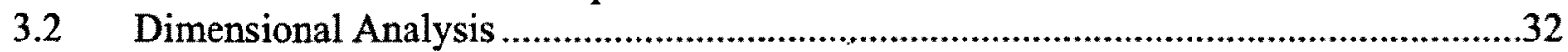

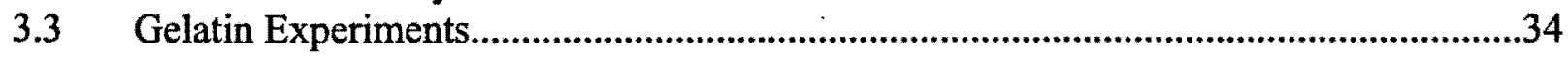

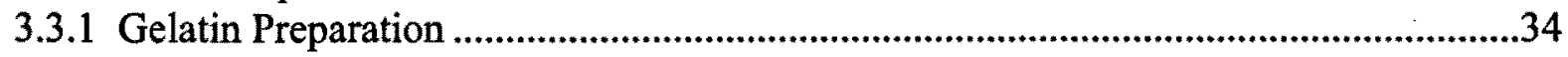

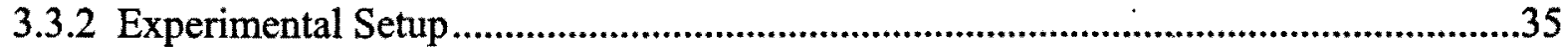

Chapter 4. Results and Discussion: Spherical Particles ......................................................... 39

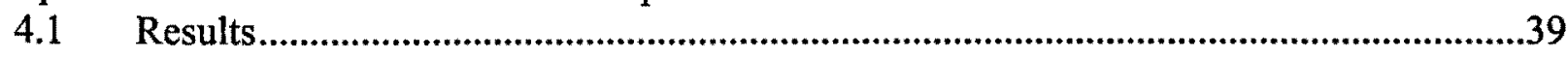

4.1.1 FE results - Estimation of material properties for calibration system..........................39

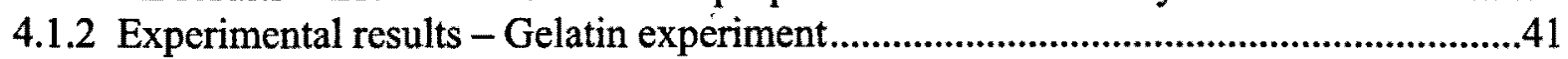

4.1.3 FE results - Estimation of material properties for model system ..................................41

4.1.4 Experimental results - Additional gelatin experiments ..................................................42

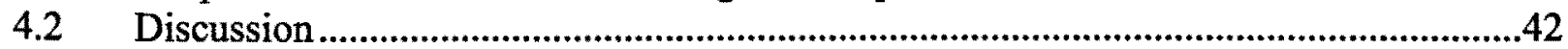

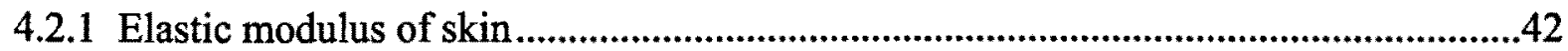

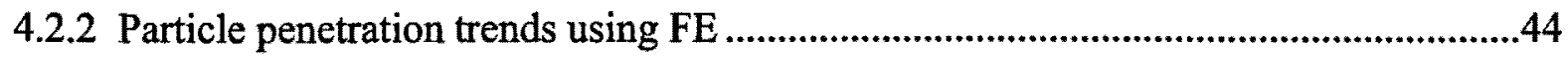

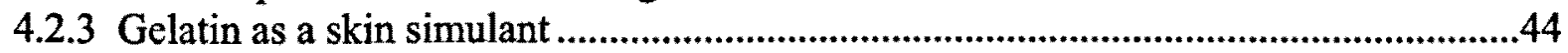

4.2.3.1 Effect of particle size on penetration depth ......................................................... 45

4.2.3.2 Effect of particle density on penetration depth ............................................... 47 
4.2.3.3 Effect of particle impact velocity on penetration depth.....................................49

4.2.3.4 Use of gelatin system to predict penetration depth in skin ................................5 50

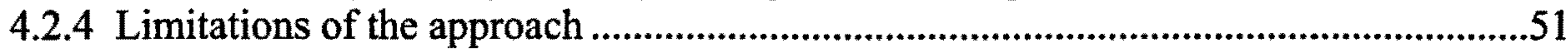

Chapter 5. Results and Discussion: Angular Particles ................................................................. 54

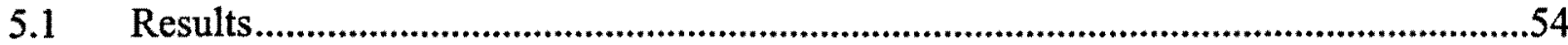

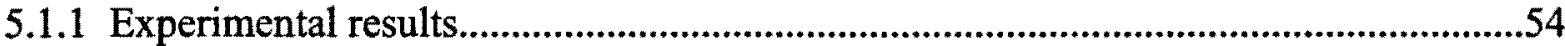

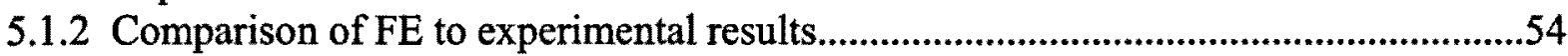

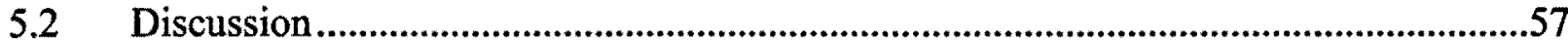

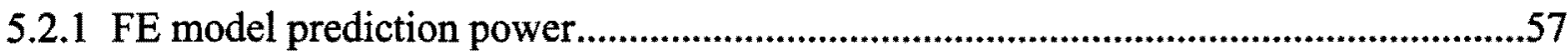

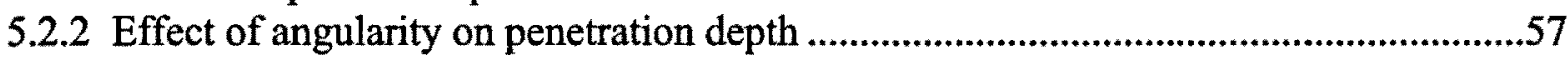

5.2.3 Implications of the study of angularity on penetration depth .....................................59

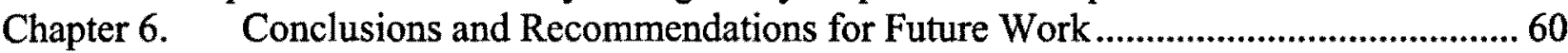

6.1 Summary of Major Conclusions and Contributions ...................................................6

6.2 Implications for the Epidermal Powder Injection Industry..............................................61

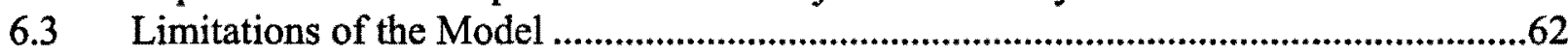

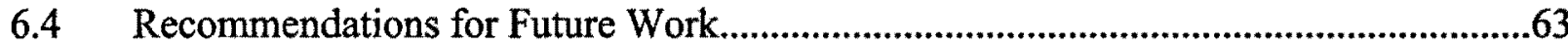

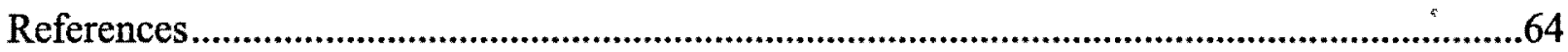




\section{LIST OF FIGURES}

Figure 2-1: The skin with its various layers and components [18]................................................... 6

Figure 2-2: Expanded mouse stratum corneum obtained from rendering [19] ................................ 7

Figure 2-3: A schematic of a commercial needle-free vaccine delivery system [24]..................... 9

Figure 2-4: Gold particles $(1 \pm 0.2 \mu \mathrm{m})$ delivered at $580 \pm 50 \mathrm{~ms}^{-1}$ into human skin [24] .............. 10

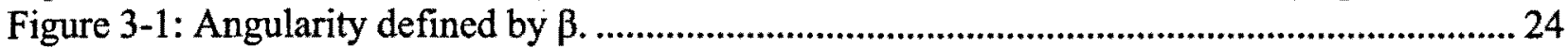

Figure 3-2: Mesh and boundary conditions used in the modeling of the particle and target. $A B=$

axisymmetric boundary. $\mathrm{OB}=$ outer boundary (fixed). All other boundaries left free...... 26

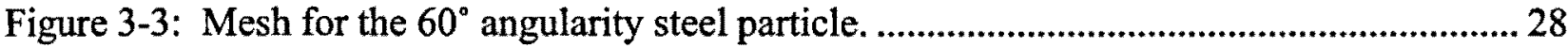

Figure 3-4: Mesh for the $45^{\circ}$ angularity steel particle. ..................................................................... 28

Figure 3-5: Element number used to mesh the skin layer versus particle penetration for a gold

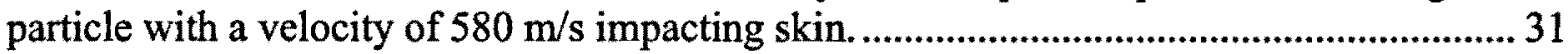

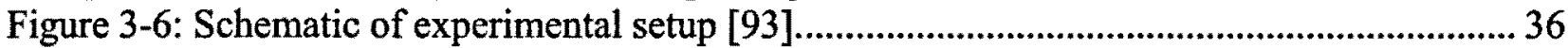

Figure 3-7: Sabots and particles employed with the gas gun in the gelatin experiments.............. 36

Figure 3-8: Multiple exposures of $3.18 \mathrm{~mm}$ steel ball in flight with the scaling bar representing

$3.18 \mathrm{~mm}$. Nitrogen gas gun pressure $=40 \mathrm{psi}$; time delay of exposures was set to $220 \mu \mathrm{s}$.

Measured distance between the exposures was $8.65 \mathrm{~mm}$, resulting in a measured speed of

$39.3 \mathrm{~m} / \mathrm{s}$

Figure 3-9: Multiple exposures of $6.0 \mathrm{~mm}, 60^{\circ}$ steel angular particle in flight with the scaling bar representing $6.0 \mathrm{~mm}$. Nitrogen gas gun pressure $=34 \mathrm{psi}$; time delay of exposures was set to $90 \mu \mathrm{s}$. Measured distance between the exposures was $5.64 \mathrm{~mm}$, resulting in a

measured speed of $63 \mathrm{~m} / \mathrm{s}$. 38

Figure 3-10: Gelatin sample with wire used to measure the particle penetration......................... 38

Figure 4-1: Gold particle impact parameter versus skin penetration depth for various particle

sizes. Data from literature [24] and FE results.

Figure 4-2: Gelatin experiments using steel balls of varying sizes and velocities; data is plotted with linear trendlines with equations given with respect to the primary axis. Secondary horizontal (top) and vertical (right) axes examine particle impact parameters and penetration of equivalent microparticles on skin.

Figure 4-3: Gelatin experiments using steel, titanium, PMMA, and tungsten carbide balls of varying sizes and velocities plotted using non-dimensional parameters. Data is plotted with

linear trendlines.

Figure 4-4: Penetrations for steel balls of diameters $1.59 \mathrm{~mm}, 2.39 \mathrm{~mm}$, and $3.18 \mathrm{~mm}$ with impact velocities of $100 \mathrm{~m} / \mathrm{s}$ plotted with a linear trendline. Secondary horizontal and vertical axes examine particle impact parameters and penetration of equivalent

microparticles on skin. 48

Figure 4-5: Effect of particle density on penetration depth for a velocity of $100 \mathrm{~m} / \mathrm{s}$ using

PMMA, titanium, steel, and tungsten carbide balls plotted with a linear trendline.

Figure 4-6: Effect of velocity on penetration.

Figure 4-7: Particle impact parameter versus penetration depth for various particle sizes; data

from literature [24] and linear extrapolation of experimental results.

Figure 5-1: Penetration results for the particle with an angularity of $60^{\circ}$ over a range of

velocities along with a linear curve fit.

Figure 5-2: Penetration results for the particle with an angularity of $45^{\circ}$ over a range of velocities along with a linear curve fit. 


\section{LIST OF TABLES}

Table 2-1: Requirements for powders applicable in needle-free powder injectors ...................... 11

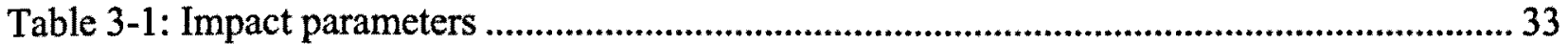

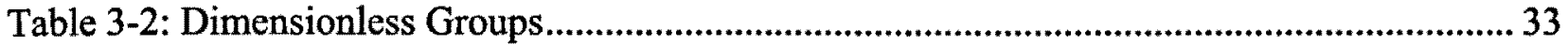

Table 4-1: Possible calibration system shear modulus - erosion strain combinations required for a $26 \mu \mathrm{m}$ penetration of $2 \mu \mathrm{m}$ diameter gold particles into skin. The model system shear modulus given by equation $4-1$, required for a $4.13 \mathrm{~cm}$ hhpenetration of a $3.18 \mathrm{~mm}$ steel sphere into gelatin is shown in the third column. .................................................................... 40

Table 4-2: Gelatin concentration and penetration data for $3.18 \mathrm{~mm}$ diameter spheres performed five times.

Table 4-3: Penetration results for balls characterized by varying sizes, densities, and impact velocities

Table 4-4: Absolute percentage difference between the equivalent gold particle penetrations found by experimentally and FE determined steel ball penetrations and the original gold particle penetration data.

Table 5-1: Penetration data for angular particles.

Table 5-2: Percentage difference between FE predicted and measured angular particle penetrations. The experimental conditions used to calibrate the two angular particle $\mathrm{FE}$ models are highlighted.

Table 5-3: Effect of angularity on particle penetration for particle having the same kinetic energy 


\section{NOMENCLATURE}

The definition of symbols in alphabetical order:

Symbol Name

$a$

A

$d$

$E$

$k$

K

$L$

m

$M_{0}$

Pd

$S$

$S_{L} \quad$ Ratio of model radius to prototype radius

$t$

$v$

$w$

Time

Particle velocity

Target width
Unit

$[\mu \mathrm{m}]$ or $[\mathrm{mm}]$

$\left[\mu \mathrm{m}^{2}\right]$ or $\left[\mathrm{mm}^{2}\right]$

$[\mu \mathrm{m}]$ or $[\mathrm{mm}]$

[Mpa]

$\left[\mathrm{Pa}^{-1}\right]$

[Non-dimensional]

$[\mu \mathrm{m}]$ or $[\mathrm{mm}]$

[kg]

$\left[\mathrm{kg} \mathrm{s}^{-1} \mathrm{~m}^{-2}\right]$

$[\mu \mathrm{m}]$ or $[\mathrm{cm}]$

$\left[\mathrm{Pa}^{2} / \mathrm{Pa}^{2}\right]$

[Non-dimensional]

[s]

$\left[\mathrm{m} \mathrm{s}^{-1}\right]$

$[\mu \mathrm{m}]$ or $[\mathrm{mm}]$

Greek symbols:
$\alpha$
Strain hardening Exponent
[Non-dimensional]
$\beta$
Angularity
[Non-dimensional]
$\varepsilon_{\mathrm{t}} \quad$ Target critical strain
$[\mu \mathrm{m} / \mu \mathrm{m}]$ or $[\mathrm{m} / \mathrm{m}]$
$\varepsilon$
Strain rate
$\left[\mathrm{s}^{-1}\right]$
$\lambda \quad$ Stretch ratio
$[\mu \mathrm{m} / \mu \mathrm{m}]$ or $[\mathrm{m} / \mathrm{m}]$
$\mu_{\infty}$
Target infinitesimal shear modulus
[kPa] or [MPa] 
$\rho_{p} \quad$ Particle density

$\rho_{t} \quad$ Target density

$\sigma$

$\phi$
Engineering stress

Strain energy density $\left[\mathrm{g} / \mathrm{cm}^{3}\right]$

$\left[\mathrm{g} / \mathrm{cm}^{3}\right]$

[Pa]

[J $\mathrm{m}^{-3}$ ]

$\mathrm{xi}$ 


\section{Chapter 1. Introduction}

\subsection{Motivation}

Drug delivery through the skin avoids many problems associated with the oral route such as: drastic changes in $\mathrm{pH}$, exposure to food and harmful digestive enzymes, variable transit times, rapidly fluctuating drug plasma concentrations, larger amounts of side effects (such as stomach pain, gas, bloating, or diarrhea), and possible patient incompliance [1]. Despite the high levels of pain, the primary method for delivery of drugs into the body continues to be the use of needles and syringes. In one study, an estimated $20 \%$ of children and $8.2 \%$ of young adults requiring vaccination demonstrated extreme distress when administered drugs using hypodermic needles [1]. A further study reported that $50-80 \%$ of all adults detailed experiencing pain and tenderness at the injection site following tetanus toxoid boosters [2]. Poor compliance to medication regimes is highly correlated to the needle aversion exhibited by many individuals, especially if requiring multiple dosages. Besides needle aversion, a second factor driving the development of a needle-free drug delivery system is concerned with the spread of blood-borne infection due to needle-stick injuries. An estimated 3 million healthcare workers are exposed to hepatitis B virus, hepatitis $C$ virus, and human immunodeficiency virus, worldwide, per year, due to impingement of a needle during treatment [2].

The investigation for useful alternatives to hypodermic needles began as far back as 1924 when Rein [3] proposed that the primary resistance to permeation transcutaneously was largely created by the most-superficial epidermal layer called the stratum corneum. Further understanding of the skin's structure and its properties led to the development of many types of needle-free transdermal delivery techniques that can be divided into passive and active methods, depending upon whether or not the drug permeation requires an external energy source. Within the realm of passive methods, the transdermal patch is in widest use, boasting $\$ 12.7$ billion in the year 2005 with an expected increase to 
$\$ 21.5$ billion in the year 2010 and $\$ 31.5$ billion in the year 2015 [4]. In spite of the success produced by products such as the nicotine patch, this type of transdermal delivery continues to be limited by the stratum corneum which acts as a barrier to molecular compounds weighing over $500 \mathrm{Da}$ [5]; in fact, the largest compound formulated within a patch is Oxybutinin, which is $359 \mathrm{Da}$ [1]. In an effort to overcome the barrier limitations, many active methods have been developed to enhance diffusion rates of the permeants, primarily through the application of electroporation or ultrasound [2]. However, despite numerous advances, certain techniques are still limited to the transmission of smaller chemicals. Additionally, passive methods are often associated with lengthy lag times, thus precluding scenarios which require rapid onset or time-varying delivery [6].

One active transdermal technique that is able to bypass the largely impermeable stratum corneum layer is a needle-free injection system that works by accelerating the pharmaceutical at speeds sufficient to blast through the outer epidermal layer. The first of such devices was developed in 1947. utilizing liquid jets and was developed to administer insulin [7]. Jet injector popularity continued to increase with the prospect of using it as a tool for vaccination. The advantages of vaccine delivery through the skin have long been known and are greater in conjunction with the use of a needleless injection system. The rationale for the development of a needle-free vaccination system include improved safety for the vaccinator, higher compliance for the vaccinee, elimination of pain at the injection site, quicker and simpler vaccination, and a potential for a reduced cost over injection using a traditional needle and syringe [2].

Another important advantage of jet injectors over other novel delivery methods is their ability to elicit a stronger immune response by delivering the vaccine-antigen directly, or in near proximity to, immunological cells such as Langerhans cells which are located in the epidermal layer of the skin [1]. The result is a possible decrease in the required dosage needed to elicit the same response. Several 
variations have been developed in an effort to optimize the jet injector's design for use as a vaccination tool. The "multi-use" nozzle was employed from the 1950 's to the 1980 's, but was discontinued as the risk for transmission of blood borne infections due to cross-contamination of the injector was deemed to be too high. Currently, there are a variety of disposable-cartridge jet injectors in use or under development which eliminate the risk of cross-contamination.

\subsection{Thesis Objective}

The purpose of the research was to determine how the initial particle and process parameters (particle incident velocity, radius, shape and density) influence the final penetration depth of particles launched at high velocity into the skin. As a consequence, a methodology for estimating the skin material parameters that govern penetration depth was developed in order to test various conditions and scenarios for implementation to transdermal powder injection.

The primary objective was fulfilled by meeting the following secondary objectives:

1. In order to overcome experimental difficulties associated with specimen to specimen variability, launching micron scale particles at extremely high velocities, and the opaque nature of skin (i.e., measurement of penetration depth), a scaled up model system consisting of an easily prepared gelatin skin simulant with impacting particles on the $\mathrm{mm}$ scale, was utilized.

2. A finite element model was established in order to determine the material parameters that could successfully describe existing penetration data from the literature for micron scale gold particles launched at very high velocity into human skin. 
3. Proper scaling laws necessary to create dynamic similitude between the two systems described in 1 and 2 were established.

4. Finite element models of both systems were utilized to investigate the appropriateness of the scaled up system to simulate the penetration of micron scale particles into the human dermis.

5. Scaled up impact experiments were performed to investigate the effect of particle size and shape on penetration depth. 


\section{Chapter 2. Literature Review}

This chapter will examine previous studies and knowledge as they pertain to the penetration of powdered pharmaceuticals into human skin via epidermal powder injection. To begin with, the skin's microstructure is examined in Section 2.1. Section 2.2 provides a general overview of powder injection including principles of operation (2.2.1), specific requirements for the drug powder formulations (2.2.2), and current limitations experienced by this type of transdermal drug delivery system (2.2.3). Finally, issues relating to the mathematical, numerical, and experimental representation of particle penetration into the skin are examined in Section 2.3 by extrapolating from ballistic studies (2.3.1), examining the measured mechanical properties of skin (2.3.2), detailing finite element models with similar characteristics (2.3.3), identifying skin simulants (2.3.4), and highlighting the use of dimensional analysis for the purpose of overcoming obstacles identified in previous studies (2.3.5).

\subsection{Skin Structure}

Optimization of a transcutaneous device design requires a solid understanding of the structure of skin. The skin is the largest organ in the human body. It has a surface area of approximately $1.5-2.0 \mathrm{~m}^{2}$, a weight of approximately $9 \mathrm{~kg}$, accounting for approximately $15 \%$ of a body's mass [8], and has an average thickness of $2-3 \mathrm{~mm}$. Each square inch $\left(6 \mathrm{~cm}^{2}\right)$ of skin holds 650 sweat glands, 20 blood vessels, 60,000 melanocytes, and more than a thousand nerve endings. It performs many important functions for the body that include being an insulator and a thermoregulator [9, 10], an input for sensory information, a site for metabolic processes, and a place for immunological activities [11, 12]. It is directly involved in the synthesis of important nutrients required by the body such as vitamin D and vitamin B [13]. Nevertheless, the skin's most important role is as a filter between the body and the external surrounding environment; it is able to selectively allow entry to some components while preventing or destroying harmful ones $[1,14]$. 
The skin is composed of three main layers; the epidermis, the dermis, and the hypodermis or subcutaneous tissue as depicted in Figure 2-1. The first two layers play an important role in the delivery of drugs while the hypodermis is mainly used for fat storage[15]. The dermal layer separates the hypodermis and the epidermis and largely consists of connective tissue which protects the body from stresses and strains. It is also the site for many important structures such as hair follicles, sweat glands, sebaceous glands, apocrine glands, blood vessels that carry nutrients and remove waste, and nerve endings responsible for sensing heat and pain [12]. The epidermis is the most superficial layer of the skin, mainly used as a waterproof, protective barrier [16]. It may be further broken down into the viable epidermis and the stratum corneum, where the viable epidermis represents the inner layer that contains living cells. There are no blood vessels in this region; cells such as Langerhans cells that are found in the epidermis are fed by diffusion from the capillaries located in the dermis [17].

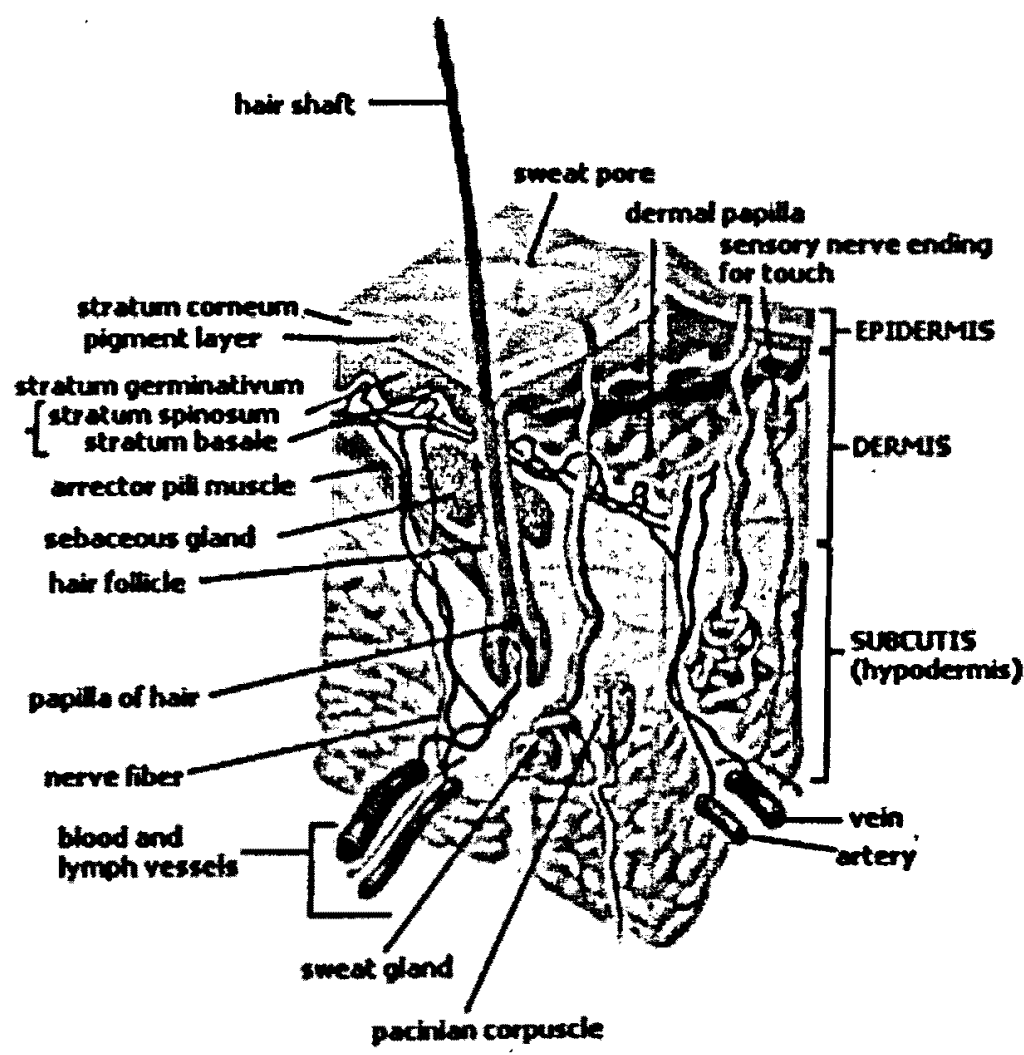

Figure 2-1: The skin with its various layers and components [18]. 
The outermost layer of the epidermis is the stratum corneum, and is the sub layer responsible for the skin's barrier characteristic due to its highly impermeable nature $[8,19,20]$. It is a heterogeneous structure composed of 10-25 layers of dead, elongated, highly keratinized corneocyte cells that are surrounded by multilamellar lipid layer as illustrated in Figure 2-2. The intercellular lipids are arranged in multiple bilayers created by bordering polar and nonpolar regions. The total stratum corneum thickness averages approximately $6-10 \mu \mathrm{m}[21]$ in all areas of the body other than in the palms of the hands and pads of the feet where the average increases by two orders of magnitude to $0.4-0.6$ $\mathrm{mm}$ [21]. $40 \%$ of the stratum corneum is composed of protein, $80 \%$ of which is the keratin that resides in the corneocyte cells [8]. The lipid layers are generally accepted to have the greatest role in determining the skin's permeability to any foreign compound [22, 23]. Regardless, as formerly mentioned, the size limit of the stratum corneum has been found to be $500 \mathrm{Da}$, thus driving the development of alternate "active" methods of transdermal delivery that require an energy input for delivery of the pharmaceutical.

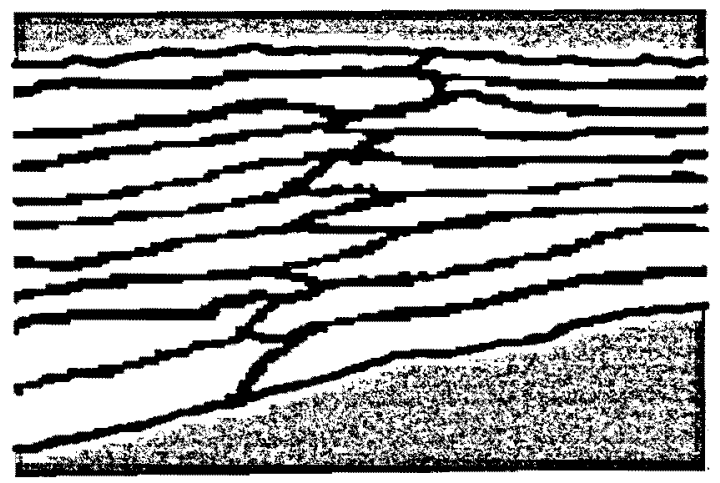

Figure 2-2: Expanded mouse stratum corneum obtained from rendering [19]. 


\subsection{Powder Injection Devices}

One particular type of jet injector currently under development is the powder injection system created by Powderject (Powderject Pharmaceuticals, plc; Contoured Shock Tube, The PowderJect Centre for Gene and Drug Delivery Research, University of Oxford, 43 Banbury Rd Oxford, OX2 6PE, UK). In this rendition, the pharmaceutical is delivered in the form of a powder rather than a liquid jet. The main advantage of using a solid particle over a liquid is in its potential for dose reduction; $1 / 2000^{\text {th }}$ dose required by epidermal powder injection is equivalent to the response elicited by the full dose required for intramuscular needle/syringe injection. Solid formulations are also advantageous in their stability during transport and storage [24], thus eliminating the need to refrigerate parenteral products sensitive to changes in temperature. In addition to dose and storage considerations, a smaller penetration into the epidermal layer ensures minimal pain and bruising with respect to their liquid counterparts [6] due to an absence of vasculature and nerve endings in the targeted region, consequently resulting in higher patient compliance, increased therapeutic success, and ultimately, greated pharmacoeconomic benefit. Reliability issues relating to the use of a single velocity jet injector found to create difficulties in obtaining correct depth and dose as a result of tissue variability may also be circumvented [25]. Use of a device similar to typical commercial powder injection systems will be the focus of this thesis, thus making worthwhile the review of operating principles and system requirements.

\subsubsection{Operating Principles}

A typical powder injection device is shown in Figure 2-3 and is composed of six main parts: a gas canister, a drug cassette, a supersonic nozzle, a rupture chamber, an actuator and a silencer. The gas canister contains the gas at a constant pressure until depression of the actuator which causes the canister to open, thus releasing the gas into the rupture chamber. The rupture chamber is broken at a critical pressure determined by the thickness of the two membranes that help to form it, thus allowing 
the gas to pass on to the supersonic nozzle. Rupture of the membrane results in the entrainment of the pharmaceutical, contained by the drug cassette, within the flow. Helium is used most often due to the high speeds that it can achieve. The system developed by Powderject is able to accelerate particles of sizes between $20-100 \mu \mathrm{m}$ to velocities of $300-900 \mathrm{~ms}^{-1}$ resulting in a delivered dose of up to $6 \mathrm{mg}$ [26], although particle payloads at $2-3 \mathrm{mg}$ are shown to produce the best bioavailability [24]. Typical depths achieved with these parameters are 20-60 $\mu \mathrm{m}$ [27]. In Figure 2-4, a histological sample is shown, illustrating the typical range of depths achieved with micron sized gold particles. A strong correlation has been determined experimentally between the initial particle velocity, radius and density, and the final penetration depth achieved by the particle [24]. Optimization of these three parameters may enable the target of specific skin layers or regions. It is important to note that the effect of particle shape is typically ignored in this approach.

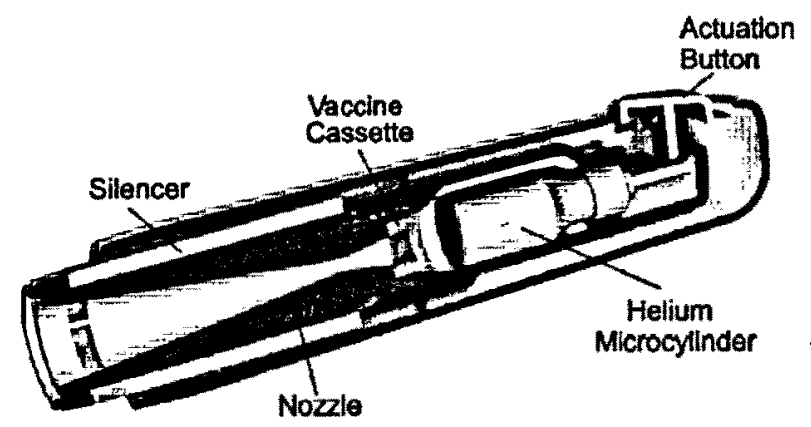

Figure 2-3: A schematic of a commercial needle-free vaccine delivery system [24]. 


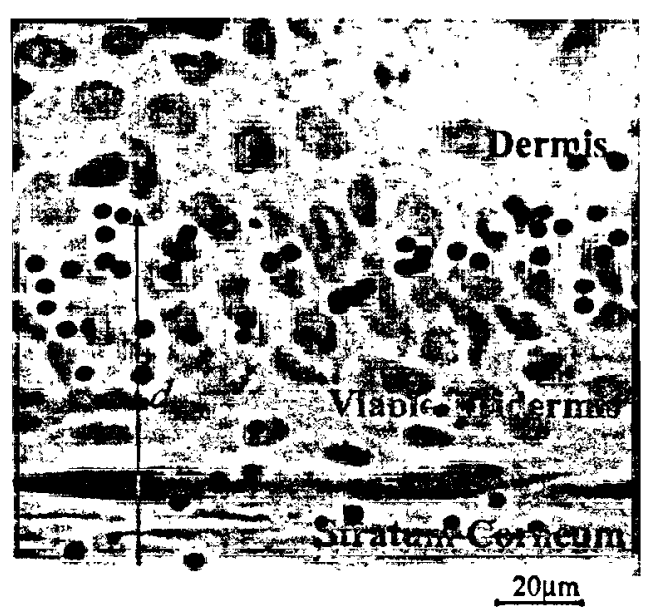

Figure 2-4: Gold particles $(1 \pm 0.2 \mu \mathrm{m})$ delivered at $580 \pm 50 \mathrm{~ms}^{-1}$ into human skin [24].

\subsubsection{Powder Requirements}

The requirements for the powdered formulations used in powder injection are similar to those for any solid dosage: drug stability; preventing chemical interaction with expients contained in the formulation or the packaging; and knowledge of effects introduced by processing and handling on particle formation [6]. Criteria specific to powder injection often involve problems arising due to the ballistic nature of the delivery where particle-particle and particle-wall collisions are frequent within the device, followed by subsequent impact with the skin's surface and penetration into the skin. In such cases, composition and processing have been found to have greater effect upon the manufactured particles' stability [26]. The processes and additives used to create the powder are chosen in order to produce optimal size, density, and strength and to ensure proper functioning of the powder throughout normal operating conditions. Expients are chosen in order to ensure the chemical and physical longevity of the drug and should enable the drug dosage to be dispensed in an appropriate manner and time interval once delivered into the body. An example is the manufacture of particles containing conventional protein subunit vaccine which is preferentially manufactured using spray-freeze-drying because of its ability to promote maintenance of spherical shape and size immediately upon freezing 
[28]. Typical expients are utilized to stabilize the protein, provide surface protection, or prevent the powder from water uptake. In addition to the stability issues created by the impact scenario, tight control over particle size and particle distribution is of great importance for precision delivery [29]. Table 2-1 lists the most desirable physical/mechanical and pharmaceutical/biological properties for particle in use in powder injection.

Table 2-1: Requirements for powders applicable in needle-free powder injectors

Physical and mechanical requirements

Uniform size ( $30-50 \mu \mathrm{m}$ in diameter)

Uniform shape (spherical)

High density $\left(800-1500 \mathrm{~kg} / \mathrm{m}^{3}\right)$

Sufficient mechanical strength to withstand impact with the skin
Pharmaceutical and biological requirements

Appropriate parenterally aceeptable excipients

Short/long-term chemical and physical stability

Appropriate biological properties, once

delivered to the skin

Manufacturability

It has been suggested that the mechanical properties most suitable for efficient drug delivery can be obtained through the concept of momentum density whereby the depth of penetration is proportional to the momentum density, given by [26]:

$$
M_{D}=\frac{v m}{A}=v d \rho_{p}=2 v a \rho_{p}
$$

where $M_{D}$ is the momentum density, and $v, m, A, d, a, \rho_{\mathrm{p}}$ are the particle velocity, mass, cross-sectional area, diameter, radius, and density respectively. Thus, to achieve a deeper penetration, the ideal particle is larger, denser and faster. $v a \rho_{\mathrm{p}}$ is typically identified as the particle impact parameter [24], 
and it has been found that a particular limiting value of $7 \mathrm{~kg} / \mathrm{m} / \mathrm{s}$ must be surpassed in order to ensure a breach of the stratum corneum. This relationship imposes practical considerations upon particle properties that have been tested and documented in the literature [30].

As previously discussed, the stratum corneum limits the passive delivery of molecules greater than $500 \mathrm{Da}$ into the skin; powder injection is said to have no upper bound on particle size because, theoretically, given sufficient incident energy, any drug formulation should have the ability to breach the skin [26]. Based on the relationship provided by momentum density for the depth of particle penetration in a homogeneous medium, it would seem that the ideal particle is larger, faster and denser. Conversely, some studies have found that the useable range of particle sizes is $20-100 \mu \mathrm{m}$. For example, the skin has been observed to deflect particles below the listed range. An exception to this observation is the DNA application particle deliveries, characterized by radii below $2 \mu \mathrm{m}$, as a result of the higher densities imparted by a gold coating [26]. At the opposite end of the spectrum, larger particles are limited by the greater incidences of biological impact such as hemorrhages and petechiae [26]. Another important particle characteristic is density, where dense particles are preferred to porous or hollow particles that may be limited by low physical strength. Higher densities ranging from 800 to $1500 \mathrm{~kg} / \mathrm{m}^{3}$ are cited as the most desirable range [29]. Further physical properties such as elasticity, plasticity, and deformability without fracture may elucidate pharmaceutical impact behaviour and efficiency of delivery. Particle shape and surface morphology are often cited as having negligible influence on performance, although the former may alter particle behaviour in gas flow [26]. Conversely, some sources cite a uniform shape, preferably spherical, as a desirable property [29].

Other processing and handling considerations specific to powder formulation for use in powder injection systems are its flowability and dosing into the gas gun cassettes, indifference to a normal range of working conditions [26], optimal storage stability, and compatibility with anticipated manufacturing 
processes [29]. Several manufacturing methods have been proposed for the formulation of the powders including spray drying (SD), spray-freeze drying (SFD), supercritical methods, fluid-bed spray coating, and many others [29], of which the first two are most promising [29, 31]. A detailed account of each process can be found in the review by Ziegler et al. [29].

\subsubsection{Current Limitations}

Although powder injection systems show a great amount of promise as an improved method of administering drugs over traditional needles and syringes, they continue to suffer certain shortcomings which limit their potential to gain widespread acceptance. The most significant problem is cited to be the development of an appropriate formulation and ensuring the development of the proper characteristics able to withstand the large forces generated in the process from drug cassette to final position within the epidermis. The combination of size, density, and particle strength are unique with respect to other solid pharmaceuticals used in pulmonary delivery or for tablet manufacture [29], thus requiring further research to establish processes that can enable this end-goal.

A further problem concerns whether or not the powder injection system is successful at eradicating pain and bruising at the injection site, two side-effects that are known to cause noncompliance in patients. To date, all powder skin injections are found to trigger a mild erythema that may be readily dissolved or may cause long-term changes to the skin's appearance and structure [26]. One study conducted by Wolf et al. [32] using the Powderject system investigated whether powder injection could provide effective skin analgesia for venepuncture in unpremedicated children. Two sites were tested; the antecubital fossa and the back of the hand. The device was found to be relatively painless and to cause only temporary changes in each of the targeted areas. However, the device was also found to be ineffective at the back of the hand. Efficiency could be increased by using higher 
driving pressures, but higher driving pressures were also found to cause a greater amount of skin damage and increased the occurrence of petechiae.

Another significant limitation to current systems is the variability in their performance represented by the scatter seen to occur in final particle position. Earlier models showed significant scatter in velocity profile and spatial distribution. This is not favourable for the proper functioning of the device throughout a range of conditions, especially in cases where specific locations must be targeted. An initial difficulty involves identifying the relationship between the initial particle parameters and the final penetration depth. Additionally, the initial particle velocity should be resolved with respect to the gas flow conditions produced by the device. The particles can only achieve a steady and reproducible velocity if they are entrained in a portion of the flow that can be represented as steady state. Ideally, the effect of each step involving the drug pharmaceutical on its efficacy must be understood. Performance is also limited to $2 \mathrm{~cm}^{2}$ impact area on the skin, and a maximum dose of approximately 6 $\mathrm{mg}[29]$.

Another possible source of penetration scatter may be a result of differences in particle size relative to cell size which may lead to different types of tissue failure, each type being associated with a different value of breaking stress [33]. The mode of penetration proposed for smaller particles is intracellular, while larger particles may penetrate by an intercellular failure mechanism. The breaking stresses associated with the intracellular mechanism are generally thought to be larger than the stresses that would cause intercellular failure since the bond between cells is not as strong as the bonds that hold the molecules of the cell together. A related problem involves the variation in the physical parameters and properties of the tissue throughout the body that have been documented for several regions [21] which may depend on the gender and age of the individual $[34,35]$. The study conducted by Wolf et al. [32] suggests that injection performance will not remain constant for any two sites on the 
body; in fact, the parameters used at one site may be completely useless at another. Understanding the relationship between the incomplete homogeneity of skin and injection efficacy may eliminate the timeconsuming process of testing each site individually.

\subsection{Modeling Particle Ballistics into the Skin}

High speed particle delivery into the skin requires the use of a model with appropriate physical characteristics that can predict the penetration of a solute with known initial parameters. The modeling of particle ballistics within the realm of powder injection is sparse. Only a single highly simplified model has been used by the group developing the Powderject system to link the initial particle parameters and mechanical properties of skin to the final particle position. The model that has been used is the theoretical penetration model first proposed by Dehn [36] which assumes that the force of deceleration acting on the particle is composed of two components: the inertial force required to accelerate the target material up to the speed of the particle, and the static force required to yield the target material [24]. This expression may be integrated to obtain the theoretical penetration depth relationship. In order to obtain penetration depth, the initial particle parameters of density, radius, and velocity must be known, as well as the yield strength of the target material, which in this case is skin. Good agreement between the theoretical model and experimental results were found using gold particles [24, 33]; however, the results highly depend upon the choice of target stiffness used [37]. The model was presented as a closed-form solution. The simplified model suffers from an inability to properly capture the complexity of human tissue, especially when subjected to large deformations and varying strain rates [38]. Furthermore, the mechanical relationship is also restricted in its ability to predict the effect of particle shape; drug particles are often assumed to be spherical [33] when in fact they are highly irregularly shaped [39]. One popular approach used to circumvent the simplicity of closed-form 
solutions in the modeling of soft materials such as skin is the use of finite element analyses with an appropriate constitutive model.

\subsubsection{Analogous Ballistic Studies}

Although no other models have been proposed for the epidermal ballistic delivery of microparticles into human skin, it is instructive to look at parallel areas of research such as wound ballistics which studies the interaction between a projectile and its target or liquid jet injection for transdermal drug delivery. The wound ballistics field of study is often concerned with the velocity required to cause a bullet of known radius and density to penetrate into the skin. For example, Jauhari et al. [40] deduced that the penetrability of skin is primarily dependent on the sectional density of the bullet, which is the mass of the bullet divided by its cross-sectional area. In addition, several relationships between threshold velocity and sectional density have been proposed [41]. Peters and Sebourn examined wound ballistics as it pertains to unstable, nondeforming projectiles $[42,43]$. This problem was broken down into different sub-processes including: projectile yaw growth and retardation, temporary cavity formation, and tissue damage. The model had the ability to ultimately predict the mean quantity of damaged tissue in addition to the expected scatter within that damage prediction. Similarly, most other studies within this realm are concerned with either threshold velocity required for penetration [44] or with amount of tissue damage [45].

Within the realm of liquid jet injection, Shergold and Fleck [46] began by examining the deep penetration of a soft solid, modeled as hyperelastic, isotropic solid, by flat-bottomed and sharp-tipped punches. Flat-bottomed punches were found to penetrate soft solids by formation of a mode-II ring crack that propagates ahead of the punch tip, while sharp-tipped punches were found to penetrate through the formation of a mode-l crack at the penetrator tip, upon which the crack may open and spread as the tip advances. In a companion paper [47], these two models were subsequently compared 
to liquid jet penetration experiments using human skin and silicon rubbers, and it was found that the sharp-tipped punch penetration model was able to sufficiently describe the pressure required to penetrate a soft solid by liquid jet. An interesting finding within the original paper was that more pressure was required to perforate the skin using the blunt-tipped punch when compared to the sharptipped punch indicating that shape of the penetrating object influences penetration depth. SchrammBaxter et al. [48] conducted a similar study with the purpose of examining the penetration mechanisms of a liquid jet into a polyacrylamide gel with varying moduli values and found that liquid penetration could be broken down into three regions: erosion, stagnation and dispersion. They also found that penetrations and erosion rates tended to decrease as the modulus value increased. The importance was placed upon the recognition that skin modulus values vary from site-to-site and person-to-person and that a sound understanding of how the jet penetration is influenced by such variations will lead to improved abilities in the drug delivery capabilities of the technology.

Although the above studies may elucidate components of the skin's behaviour upon puncture and penetration it must be noted that in the study of liquid jet injection, the penetration is on the order of several millimeters where the dermis largely influences overall epidermal behavior. Ballistic studies are often concerned with deeper penetrations, through the dermal region and into underlying musculature or organs $[49,50]$. Conversely, powder injection is only concerned with penetration at the micron scale where skin behaviour and penetration mechanism may be largely different. Experimental studies examining powder injection are often concerned with the percentage of cassette dose that reaches specific layers of the skin as a function of actuating device pressure, but they are not concerned with the formation of mechanisms that can directly link initial particle and process parameters to final penetration depth [39]. 


\subsubsection{Measured Mechanical Properties of Skin}

Many attempts have been made to determine the mechanical properties of the various layers of the skin using techniques such as the tensile [51-53], compressive [54-57], indentation [58, 59], torsion [60], and suction $[61,62]$ tests. However, the values taken from these quasi-static tests may not be applicable to the study of the high-strain rate particle ballistic impact that is typical of powder injection technology $[24,33]$. Strain rates representative of most mechanical tests on skin are approximately ten orders of magnitude smaller than the strain rates that characterize particle penetration using powder injection [37]. During a study on the effects of relative humidity and ambient temperature on the ballistic delivery of micro-particles to excised porcine skin, Kendall et al. [37] determined that the use of a yield stress value obtained from a tension test would result in an overestimation of the predicted penetration depths by a factor of 6 . Furthermore, the value of yield stress needed to accurately predict penetration depth would have to be more that 10 times higher than the quasi-static value. One of the proposed reasons is that the material undergoes a ductile-to-brittle transition with increasing strain rate and will exhibit different modes of failure. Shergold and Fleck have also examined the effect of strain rate on the shear modulus of porcine skin [63], finding an increase in modulus value by a factor of five as the strain rate increases from $\dot{\varepsilon}=0.004 \mathrm{~s}^{-1}$ to $\dot{\varepsilon}=40 \mathrm{~s}^{-1}$, and by a further factor of four between strain rates $\dot{\varepsilon}=40 \mathrm{~s}^{-1}$ to $\dot{\varepsilon}=4000 \mathrm{~s}^{-1}$. A further consideration may relate to the mechanical model utilized to determine the Young's modulus from the tensile tests performed by Wildnauer et al. [64] and subsequently used by Kendall et al. [37] that lead to an erroneous value of penetration depth [38, 61]. Most mechanical models do not account for the large effect of external variables, such as the type of stress applied, the thickness of skin, and the surface area of tissue used, all of which may significantly alter the measured elastic modulus [38]. In reality, the values for measured Young's moduli have been found to vary by a factor of 3000, e.g., from $0.02 \mathrm{MPa}$ to $57 \mathrm{MPa}$ [61], depending upon the model proposed. 


\subsubsection{Finite Element Modeling of Skin}

Not only has the structure of skin been well recognized for years, but it is also widely accepted that the behaviour of skin is properly described as a nonlinear, anistropic, viscoelastic material $[51,53$, 65-67] in a state of tension in vivo [68]. Several constitutive relationships have been proposed for the purpose of analyzing skin tissue. These can be broken down into micromechanical or phenomenologically-based models [63]. Micromechanical models incorporate physiologically meaningful parameters to characterize the behaviour of skin. In this way, a change in one or more parameters would represent the structural differences between two samples and, additionally, have the ability to predict the difference in their observed responses. Some micromechanical models examine only one component of the skin, such as a single collagen fibre [69], while Bischoff et al. [70] was able to formulate a model describing the collagen network present in the dermis, in terms of collagen density and fibre free length.

Phenomenological models, on the other hand, put forth a strain energy density function to describe the skin's constitutive response. One of the first strain energy functions was proposed by Fung in 1973 [71] who asserted that an elastic modulus value was meaningless without an associated stress level. He proposed an anisotropic exponential strain energy equation that could be fitted to biaxial tension tests performed on excised rabbit skin $[66,72]$. Other strain energy functions have been formulated by Barbanel [73], Wijn [74], and Oomens [57], each of which was fitted to successfully describe one type of histological behavior [62]. Although some attempts have been made to develop closed-form solutions to such formulations [38, 51, 61, 75], related parameters may be difficult to analyze and identify [76], or, more frequently, simplifications made to geometry and boundary conditions may result in models that can only successfully describe skin behavior for a single loading scenario only [38]. 
The development of more accurate geometry and boundary conditions necessitates the implementation of a numerical analysis. This allows for the description of complex behaviours, such as skin wrinkling [77] and wound closure [78], as well as more accurate multilayered structures [62, 77]. Finite element modeling can also account for large deformations and large strains [79] common to high impact, ballistic studies which are especially difficult to analyze in soft tissues. In such applications, it is commonplace to treat skin tissue as an incompressible, hyperelastic solid that can be represented with an Ogden constitutive model, capable of describing a wide range of strain-hardening behaviors [46]. Another hyperelastic constitutive model, the Mooney Rivlin formulation, has been employed with a lesser degree of accuracy due to its inability to properly capture the behavior of materials with extremely strong strain hardening capacities $[63,80]$.

\subsubsection{Skin Simulants}

An obstacle to preventing a more comprehensive understanding of particle penetration into the skin concerns the micron-size scale of typical pharmaceutical powders, as well as the opaque quality of skin, creating difficulties in visualizing and quantifying the effect of particle size, shape and orientation upon entry into the epidermis. Gels have often been used in ballistic studies to simulate soft tissue and muscle deformation in the examination of bullet trauma and injuries [15-19], as well as in the examination of liquid jet penetration of the skin [48]. The suitability of gelatin in these studies stems mainly from its transparency and controllable dimensions, as well as the ease with which the mechanical properties can be altered through manipulation of gelatin weight percent in the formulation [48]. A literature search showed that gels are very rarely used to simulate skin; most often, silicon rubbers are used due to the likeness of their moduli to that of skin. One exception can be found in the study examining gelatin as a suitable skin simulant in the analysis of the penetration mechanisms of a liquid jet into an analogous soft solid [20]. However, the emphasis in this particular study includes the contribution of the larger dermis and hypodermis layers that dominate and characterize the overall 
mechanical response of the material. Another study concerned with the efficacy of powder injection systems used gels to model the stratum corneum and viable epidermis layers. In this case, upon release from the injection apparatus, the drug was collected from each layer but individual penetrations were not examined.

\subsubsection{Dimensional Analysis}

Scale models have often been used in ballistic penetration studies when the feasibility of a full scale test is low, generally due to a high associated experimental cost. High strain rate penetration events are simulated on the smaller scale using a gas gun in conjunction with particles reduced in size. The data in these experiments can often be scaled to obtain results pertinent to the prototype model for which it is supposed to replicate using appropriate scaling laws. A dimensional analysis is typically employed to formulate the rules which elucidate the relationship between the two systems. For example, the Buckingham Pi theorem [81] requires that all the relevant parameters for the problem in question be combined into dimensionless groups. The choice of the parameters depends on the problem; for example, when utilizing an FE model, the parameters characterizing the constitutive model (i.e., the material parameters), the geometric parameters, and the response parameters dictated by the scenario must all be considered. The dimensionless groups for each system must be identical to each other in order to attain the necessary criteria of similitude. If all the criteria are met, the results from one system may be scaled using the scaling laws to reflect the results in the related system.

Although most ballistic penetration studies have utilized a smaller system to mimic a full scale problem, the present work will examine the use of a scaled-up (i.e., larger dimensions) model to simulate the interaction between the powdered drug particle and the epidermal layer. In this manner, a skin stimulant (i.e., a model material which acts like skin when appropriately scaled) with desirable 
properties such as transparency and repeatability may be used as a substitute for skin, enabling a more comprehensive examination of the impact scenario. 


\section{Chapter 3. Materials and Methods}

This chapter describes the several inter-related steps that were used to build a finite element model which could be experimentally verified using scaled up experiments, and ultimately used to predict the penetration of particles into the epidermis.

(i) A finite element model of a calibration system involving the impact of a $2 \mu \mathrm{m}$ diameter gold sphere with a velocity of $651 \mathrm{~m} / \mathrm{s}$ on human skin was constructed (Section 3.1). Under these conditions, Kendall et al. [24] measured an average gold sphere penetration of $26 \mu \mathrm{m}$ based on 401 data points with a standard error of $\pm 18 \mu \mathrm{m}$. The finite element model was used to determine the combinations of skin material properties that would yield this penetration.

(ii) A dimensional analysis, described in section 3.2, was performed that linked the calibration system of (i) to a model system which utilized $3.18 \mathrm{~mm}$ steel balls impacting a gelatin. An FE model for the steel ball-gelatin system was created in order to confirm the dimensional analysis. The analysis allowed the penetration data of Kendall et al. [24], i.e. for the impact of $1 \mu \mathrm{m}$ radius gold spheres on human skin, to be converted to an equivalent penetration for the model steel ball-gelatin system. For the calibration system of (i), the equivalent steel ball velocity was $83 \mathrm{~m} / \mathrm{s}$, and the equivalent penetration was $4.13 \mathrm{~cm}$.

(iii) Impact experiments were performed on the model system with gel formulations having varying gelatin concentrations with known mechanical properties, and the resulting steel ball penetrations were measured (Section 3.3). The gel formulation which resulted in the steel ball penetration to that was closest to that corresponding to the calibration data (i.e., $4.13 \mathrm{~cm}$ ) was determined. The gelatin material properties corresponding to this formulation were converted to dimensionally similar material properties for the calibration system (i.e. skin). These properties were used to choose the best set of skin material properties from the list generated in (1). 
(iv) The skin material properties determined in (iii) were used in new FE simulations of particle penetration into human skin, in order to determine the effect of varying particle size, density and velocity on the resulting penetration depth.

(v) The gelatin system chosen in step (iii) was subjected to high speed impacts of steel, titanium, PMMA, and tungsten carbide balls of varying diameter and density in order to determine whether the trends found in skin were also found when using this scaled up system, i.e., whether gelatin was an appropriate skin simulant. Angular particles (angularity of $45^{\circ}$ and $60^{\circ}$ ) made of steel with a side dimension of 6.0 $\mathrm{mm}$ were also tested to determine the effect of angularity on penetration. A figure defining angularity is shown in Figure 3-1.

These steps are described in detail in the following sections.

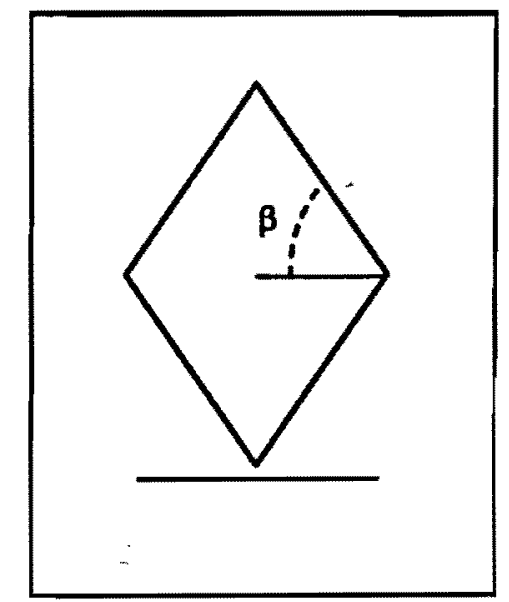

Figure 3-1: Angularity defined by $\beta$. 


\subsection{Finite Element Models}

The explicit finite element code LS DYNA 971 (Livermore Software Technology Corporation, Livermore, CA, USA) was used to construct FE models of the calibration gold particle - skin system as well as the model steel bearing - gelatin system. The model was used to elucidate the material properties of skin, validate analytically obtained scaling laws, and verify particle impact trends found in the literature and experiments. To simplify the analysis and allow for the construction of an appropriate scaled-up model using the gelatin, the stratum corneum and viable epidermis were modeled as a single homogeneous isotropic layer, a common simplification utilized in the examination of dynamic problems involving complex, layered material such as skin [47]. The hypodermis was neglected due to its low stiffness in relation to the superficial layers [38]. It was also found that the presence of the dermis could be neglected, since the difference in the simulated particle displacement with the lower boundary fully constrained and unconstrained produced a difference of only $4.8 \%$.

The modeled skin layer was assumed to be isotropic with semi-infinite dimensions in the direction parallel to the skin's surface, while the thickness was taken to be $75 \mu \mathrm{m}$, equal to the combined dimensions of the stratum corneum and viable epidermis [37, 82, 83]. Different layer lengths were tested in order to ensure negligible boundary effects upon particle displacement; a length-toradius ratio of 5 was found to be adequate. The dimensions in the larger gelatin model were scaled by a factor $S_{\mathrm{L}}$ equal to the ratio of model and prototype characteristic lengths, given by the particle radii of $1.59 \mathrm{~mm}$ and $1 \mu \mathrm{m}$ respectively:

$$
S_{L}=\frac{a_{\text {MODEL }}}{a_{\text {PROTOTYPE }}}
$$

where $a$ represents the particle radius. 
The symmetry resulting from the use of a spherical particle enabled implementation of an axisymmetric formulation. The outside boundary was constrained for all displacements and rotations, due to treatment of skin as an infinite medium, whereas the boundary along the axisymmetric edge was allowed displacement in the direction perpendicular to the skin's surface only. The bottom of the model representing the boundary between the viable epidermis and the dermis was left constraint-free. An initial particle velocity, found from literature in the case of the gold particle and from experimentation for the larger-scale balls, was prescribed to the particle. The geometry, boundary conditions and loading conditions are illustrated in Figure 3-2. Frictionless contact between the projectile and the target was assumed.

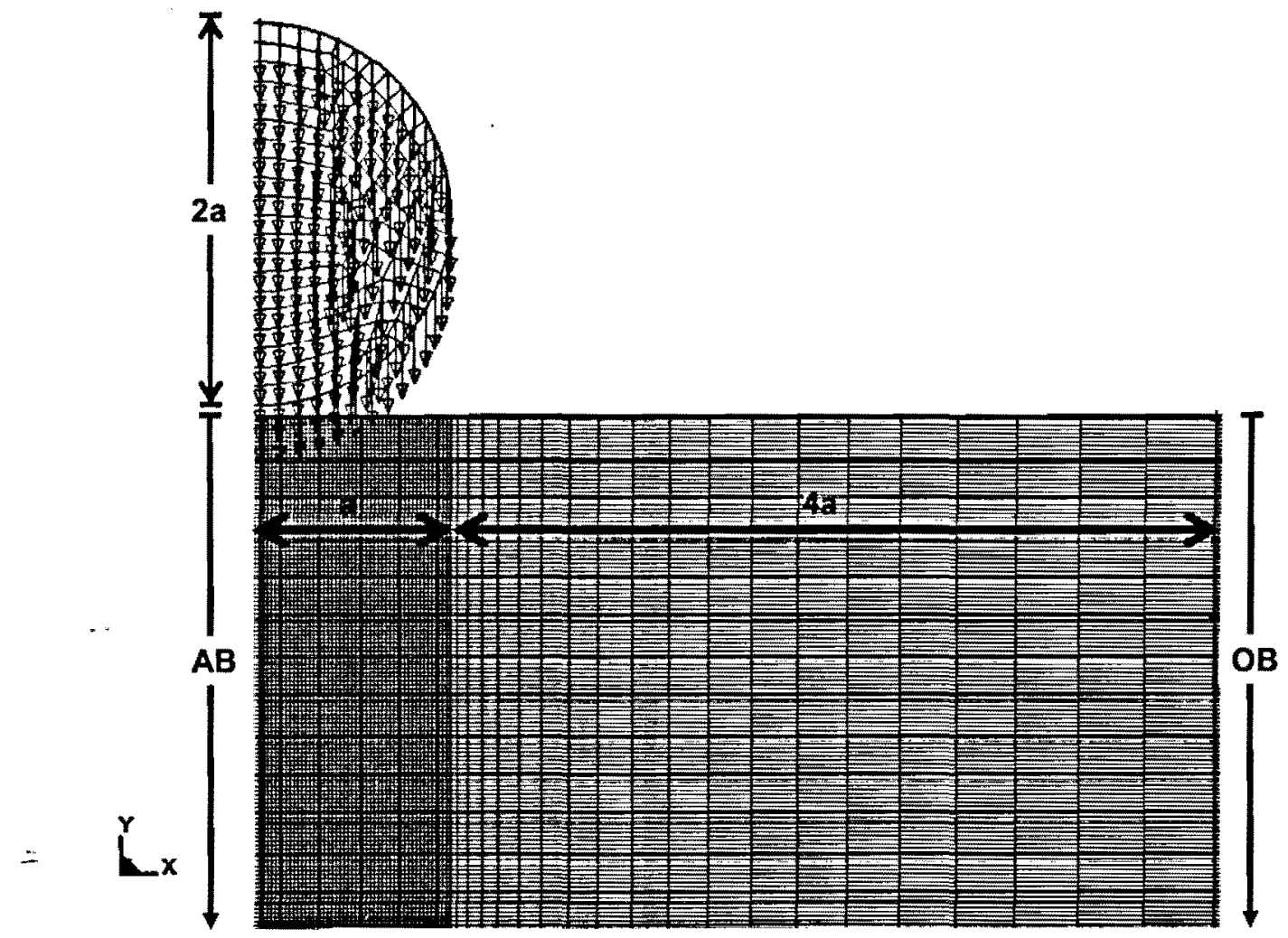

Figure 3-2: Mesh and boundary conditions used in the modeling of the particle and target. $A B=$ axisymmetric boundary. $\mathrm{OB}=$ outer boundary (fixed). All other boundaries left free. 
The particle (i.e., either gold, steel, titanium, PMMA or tungsten carbide) and target (i.e. either skin or gelatin) were both meshed with four-noded reduced shell elements. Two different mesh densities were used to mesh the area representing the target. The impact region, represented by a width of $a$, was given a finer mesh, and the outlying region of width 4 a was given a graded mesh as depicted in Figure 32. In total, the skin contained 220,663 nodes and 204,750 elements, while the particle had 185 nodes and 160 elements. The gold and steel particles were both modeled to be linear elastic with a Young's modulus of $79 \mathrm{GPa}$ and $210 \mathrm{GPa}$ respectively.

For the models utilizing particles having smaller radii than $1 \mu \mathrm{m}$ in the case of gold and $1.59 \mathrm{~mm}$ in the case of the larger steel, titanium, and tungsten carbide balls, the model dimensions were scaled according to Equation 3-1. As was the case with the steel and gold particles, the titanium, PMMA and tungsten carbide particles were modeled to be linear elastic with a Young's modulus of $100 \mathrm{GPa}, 2.45$ GPa and $550 \mathrm{GPa}$ respectively. However, it was necessary to increase the mesh in the impact region to 252,000 elements, and to 84,000 elements in the outer region. The mesh given to the sphere was left unchanged.

In the case of the FE model of the $6.0 \mathrm{~mm} 60^{\circ}$ steel angular particle, shown in Figure 3-3, the mesh of the skin target remained the same while the particle was meshed with 146 nodes and 104 elements. Also unchanged was the modeling of the particle as an elastic solid with an elastic modulus value of $210 \mathrm{GPa}$, a density of $7610 \mathrm{~kg} / \mathrm{m}^{3}$, and a Poisson's ratio of 0.3 . For the $5.83 \mathrm{~mm}$-sided $45^{*}$ square particle, due to a technical issue with meshing in LS DYNA, it was necessary to create a full model (rather than a symmetric half). This model had 315,000 nodes and 304,413 elements representing the skin, and 440 nodes and 361 elements for the particle, as shown in Figure 3-4. The material properties remained unchanged. 


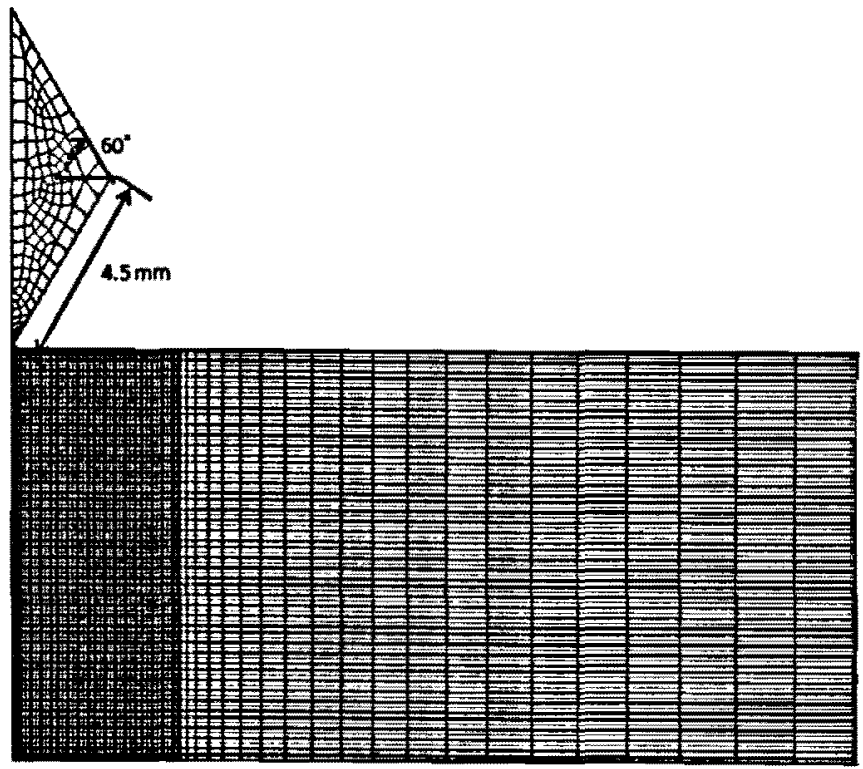

Figure 3-3: Mesh for the $60^{\circ}$ angularity steel particle.

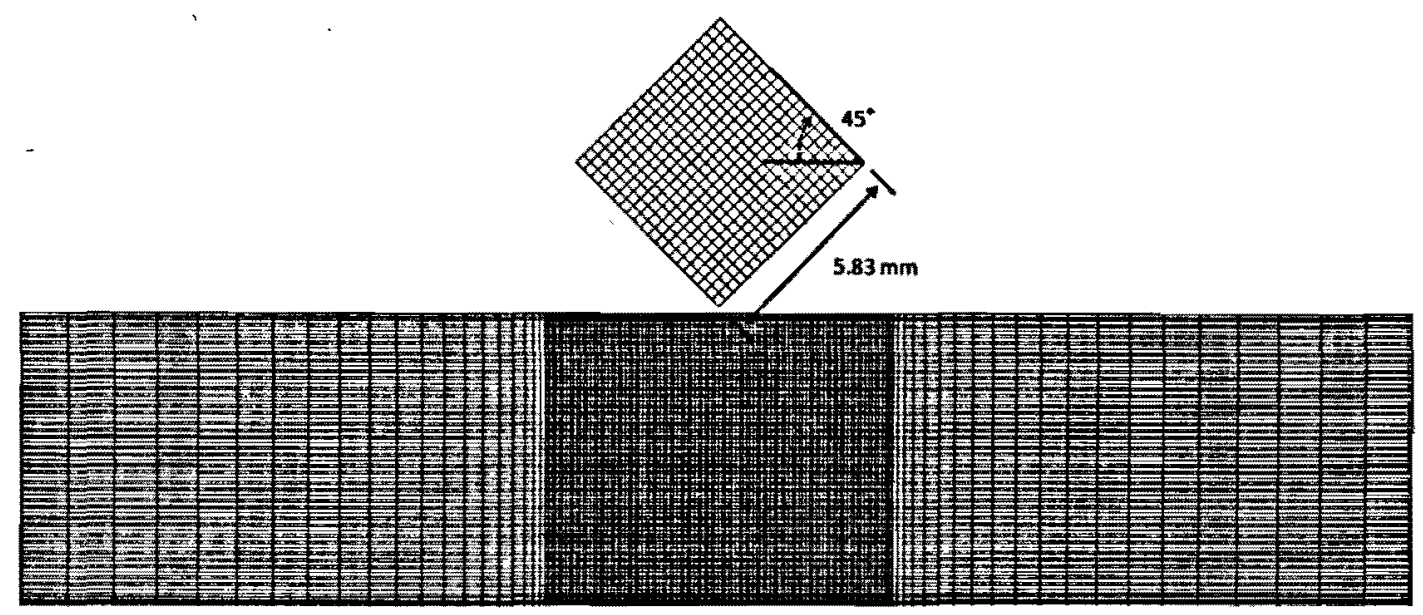

Figure 3-4: Mesh for the $45^{\circ}$ angularity steel particle.

\subsubsection{Constitutive model of skin and gelatin}

The Ogden model [84] which has been used successfully to model the behaviour of many types of biological tissue, including skin [46], was used to model both the human skin and gelatin. The 
material model demonstrates a nonlinear relationship between stress and stretch. For the high strain rates involved in particle impact, time-dependent effects may be disregarded [85], since the modulus value plateaus at high strain rates. In the case of the gelatin experiments, the maximum strain rate was on the order of $10^{5} \mathrm{~s}^{-1}$ as measured by the FE models, and Kendall et al. [37] had estimated strain rates on the order of $10^{6} \mathrm{~s}^{-}$in their tests of gold particle penetration of skin. Assuming an incompressible solid, the one term Ogden function employed in the present study takes the form of [63]:

$$
\varphi=\frac{2 \mu_{\infty}}{\alpha^{2}}\left(\lambda_{1}^{\alpha}+\lambda_{2}^{\alpha}+\lambda_{3}^{\alpha}-3\right)
$$

where $\phi$ is a strain energy density function characterized by the infinitesimal shear modulus $\mu_{\infty}$, responsible for describing the material's stiffness, the strain hardening exponent $\alpha$, a measure of the material's strain hardening potential, and the principal stretches $\lambda_{1} \lambda_{2} \lambda_{3}$. The stress-stretch relationship may be obtained by taking the derivative of Equation $3-2$ with respect to $\lambda$. Furthermore, if the impact path is collinear with the z-axis of a Cartesian co-ordinate system, and if the target is considered to be in a state of uniaxial stress, the stress-stretch ratio can be reduced to [63]:

$$
\sigma_{z}=\frac{2 \mu_{\infty}}{\alpha}\left[\lambda_{z}^{\alpha-1}-\lambda_{z}^{-1-(\alpha / 2)}\right]
$$

where $\sigma_{z}$ represents the $1^{\text {st }}$ Piola-Kirchoff stress (i.e., the nominal stress).

A curve fitting procedure was employed to determine the $\mu_{\infty}$ and $\alpha$ values that minimized the least squares error, $S$, between the experimentally measured stress and the stress calculated using Equation 3-3 during a unlaxlal tension or compression test [63]: 


$$
S=\sum_{k=1}^{K}\left(\frac{\sigma_{k}-\hat{\sigma}_{k}}{\sigma_{k}}\right)^{2}
$$

where $\widehat{\sigma}_{k}$ is the engineering stress from Equation 3-4, $K$ is the number of data pairs $\left(\lambda_{k}, \sigma_{k}\right)$ in the test data set, and $\lambda_{k}$ and $\sigma_{k}$ are the stretch ratio and the engineering stress measured during the test, obtained from studies in the literature [86-88].

In the FE simulation of projectile impact and penetration problems, element erosion is often utilized in order to simulate material cutting, while avoiding the presence of highly distorted elements that might cause numerical instabilities [89]. In such schemes, a particular element is removed from the mesh upon reaching a critical principal stress or strain value. The present work incorporated a critical erosion strain criterion for element erosion, which was treated as a free parameter that was adjusted for a best fit to experimental data. The critical erosion strain was different depending on whether the particles were spherical or angular; this is discussed in more detail in Section 3.1.3.

\subsubsection{FE model mesh sensitivity}

A mesh sensitivity analysis was conducted in order to determine the best trade-off between FE model convergence and computational time. Using an infinitesimal shear modulus of $4.2 \mathrm{MPa}$ and an erosion strain of 0.6 to characterize the skin, 5 different mesh densities were utilized, and the resulting particle penetration depths are shown in Figure 3-5. On an Intel Quad CPU, at $2.4 \mathrm{GHz}$ with $3.00 \mathrm{~GB}$ of RAM, the computational time varied from $5.5 \mathrm{hr}$ for the mesh with 56,000 elements, to $56.5 \mathrm{hr}$ for the mesh with 288,750 elements. The percent difference between the mesh having 204,750 elements versus the mesh having 288,750 was only $2.41 \%$, and thus the mesh with 204,750 elements, provided a good trade-off between the estimated error and the time required $(38.5 \mathrm{hr})$ for solution. 


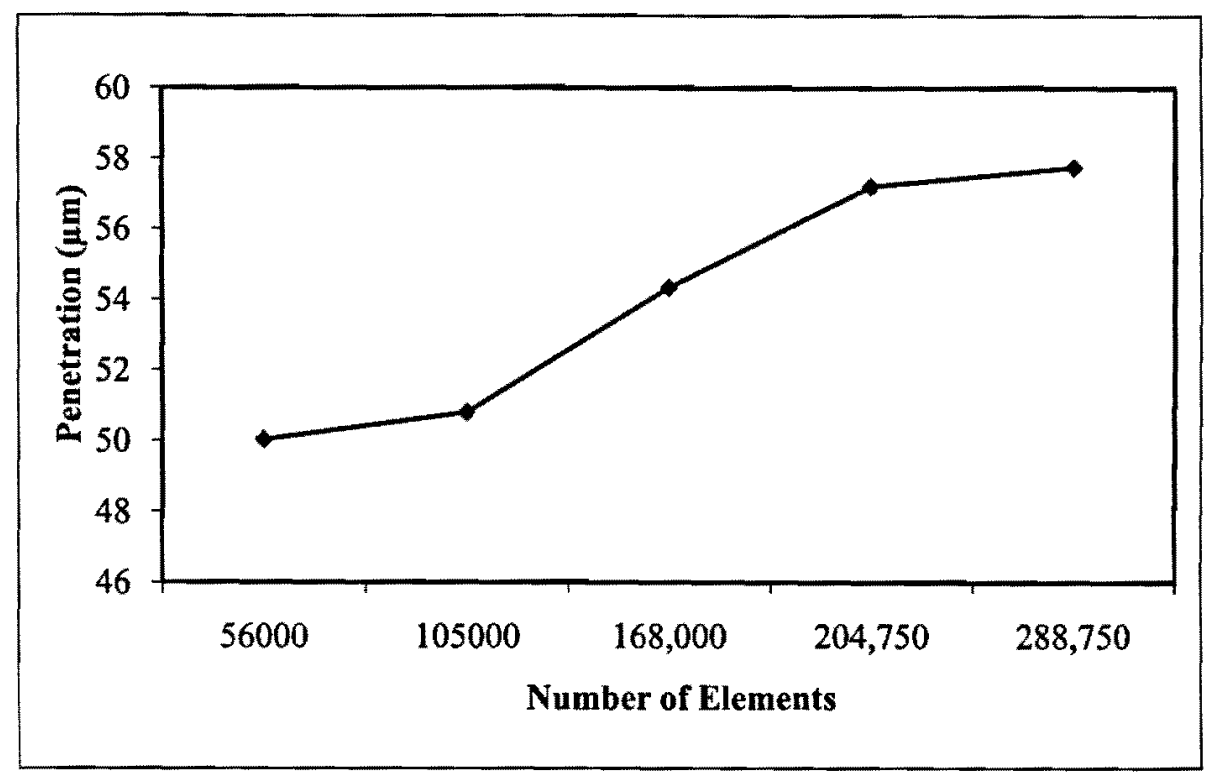

Figure 3-5: Element number used to mesh the skin layer versus particle penetration for a gold particle with a velocity of $580 \mathrm{~m} / \mathrm{s}$ impacting skin.

\subsubsection{Estimation of Material Properties of Skin}

In order to determine the infinitesimal shear modulus of the skin at strain rates in excess of $10^{6}$ $s^{-1}$, the experimental data of Kendall et al. [24] were used to calibrate the finite element model. Kendall et al. [24] launched $0.4-2.4 \mu \mathrm{m}$ radius gold spheres against samples of human skin, and plotted the resulting penetration as a function of a parameter, called the particle impact parameter, $\rho v a$, where $\rho$, $v$, and $a$ are the particle density, velocity, and radius, respectively, a representation of the momentum per cross-sectional area of the particle. For the chosen prototype system consisting of $1 \mu \mathrm{m}$ radius gold particle traveling at $651 \mathrm{~m} / \mathrm{s}, \rho v a=10.94$, and the measured penetration from [24] was $26 \mu \mathrm{m}$.

Using the calibration gold particle - skin system finite element model, a parametric study was undertaken to identify combinations of skin infinitesimal shear modulus and critical strain that yielded this $26 \mu \mathrm{m}$ penetration. The choice of critical erosion strain was limited to the reported range for the 
maximum critical strain of pig skin [90] (range: $0.00-1.00$, median: $0.3-0.55$ ), the skin type most closely resembling human skin in structure and properties. It should be noted that values for ultimate strain in human skin agree with the median values reported for pig skin [91, 92], but decrease at higher strain rates [92]. The results of this parametric study are discussed in Section 4.1.1.

In the case of the angular particles, the modulus value resulting from the parametric study was used; however, the erosion strain was adjusted to fit one set of experimental conditions and then utilized in all other cases.

\subsection{Dimensional Analysis}

A dimensional analysis was conducted in order to ensure similitude between the calibration system gold particle impacting the skin and the scaled-up model utilizing steel spherical particles with a gelatin target. The material parameters pertinent to the material model and geometry employed in the finite element analysis are listed in Table 3-1 along with typical units and fundamental dimensions for each. Application of the Buckingham Pi Theorem [81] resulted in 10 dimensionless groups that were classified as geometric, material characterization, or response, as depicted in Table 3-2.

The geometric groups describe the geometrical scaling of the two systems. $\pi_{3}$ relates the incident energy of the particle to the particle's ability to absorb energy in the elastic range, while $\pi_{4}$ is the kinetic energy per unit volume imparted to the target divided by the amount of energy per unit volume that can be absorbed by the surface. $\pi_{5}$ is a measure of the inertial disparity between the particle and target. $\pi_{6}$ and $\pi_{7}$ further characterize the material parameters of the target, while $\pi_{8,} \pi_{9}$ and $\pi_{10}$ relate to the response of the target upon impact, in particular, to the penetration, strain rate, and time of the response. 
Table 3-1: Impact parameters

\begin{tabular}{|c|c|c|c|}
\hline Parameter & Description & Typical units & Fundamental units \\
\hline$a$ & Particle radius & (m) & $\mathbf{L}$ \\
\hline$\rho_{p}$ & Particle density & $\left(\mathrm{kg} \mathrm{m}^{-3}\right)$ & $M L^{-3}$ \\
\hline$E$ & Particle elastic modulus & $(\mathrm{Pa})$ & $M T^{-2} L^{-1}$ \\
\hline$L$ & Target length & (m) & $\mathbf{L}$ \\
\hline$w$ & Target width & (m) & $L$ \\
\hline$\rho_{t}$ & Target density & $\left(\mathrm{kg} \mathrm{m}^{-3}\right)$ & $M L^{-3}$ \\
\hline$\mu_{\infty}$ & Target infinitesimal shear modulus & $(\mathrm{Pa})$ & $M T^{-2} L^{-1}$ \\
\hline$\alpha$ & Target strain hardening exponent & - & - \\
\hline$\varepsilon_{\mathrm{t}}$ & Target critical strain & - & - \\
\hline$v$ & Impact velocity & $(\mathrm{m} / \mathrm{s})$ & $L T^{-1}$ \\
\hline$P_{d}$ & Penetration depth & $(\mathrm{m})$ & $\mathbf{L}$ \\
\hline$\dot{\varepsilon}$ & Strain rate & $s^{-1}$ & $T^{1}$ \\
\hline$t$ & Time & s & $T$ \\
\hline
\end{tabular}

Table 3-2: Dimensionless Groups

\begin{tabular}{ccc}
\hline Geometric & Material characterization & Response \\
\hline$\pi_{1}=\frac{L}{a}$ & $\pi_{3}=\frac{\rho_{p} v^{2}}{E}$ & $\pi_{8}=\frac{P_{d}}{a}$ \\
$\pi_{2}=\frac{w}{a}$ & $\pi_{4}=\frac{\rho_{t} v^{2}}{\mu_{\infty}}$ & $\pi_{9}=\dot{\varepsilon} \frac{a}{v}$ \\
$\pi_{5}=\frac{\rho_{t}}{\rho_{p}}$ & $\pi_{10}=t \frac{v}{a}$ \\
$\pi_{6}=\alpha$ & \\
$\pi_{7}=\varepsilon_{t}$ &
\end{tabular}




\subsection{Gelatin Experiments}

The gelatin experiments were conducted for two principal reasons. Firstly, they were used in conjunction with the dimensional analysis to help select a set of material parameters that could adequately describe the skin target of the prototype system. Secondly, these experiments were conducted in order to determine whether gelatin is in fact a suitable skin simulant by examining equivalent gold particle-skin penetrations with the non-dimensional groups and by observing whether trends of size, density and velocity found in skin could be determined using gelatin as well. Furthermore, use of gelatin as a skin simulant enabled the determination of the effect of angularity on penetration.

\subsubsection{Gelatin Preparation}

In order to obtain a gelatin with the correct properties necessary for dynamic similitude with the prototype system, it was necessary to vary the concentration and ageing conditions from the standard ballistic formulation of $10 \mathrm{wt} \%$ aged for 24 hours at $10^{\circ} \mathrm{C}$ in accordance with the factors given by Bot et al. [86]. The samples were made with Knox gelatin following the procedure recommended by Bot $e$ t al. [86] using cylindrical plastic moulds characterized by a diameter $7.5 \mathrm{~cm}$ and a depth of $10 \mathrm{~cm}$. Gelatin samples with concentration of 7,8 , and $12 w t \%$ were made, having shear moduli values of $3.77,5.67$, and $11.64 \mathrm{kPa}$ respectively, found by curve fitting the experimental data as provided by Bot et al. [86] to the Ogden model. A 10 wt\% formulation was also made, but since a curve for this formulation was not included in the Ref. [83], the shear modulus was extrapolated from the data for the other gelatin formulations; i.e. the modulus was found by curve-fitting the three shear modulus values given above to the power law relationship [86]:

$$
\mu_{\infty}=k c^{1.8}
$$


where $c$ is the concentration in weight percent, $\mu_{\infty}$ is the shear modulus in Pascals, and $k$ is a proportionality constant. The R-squared values of all the curve fitted experimental data were very close to 1 . In this manner, the shear modulus value for $10 \mathrm{wt} \%$ was found to be $8.61 \mathrm{kPa}$. Since the experiments of Bot et al. [86] were performed under quasi-static conditions, a scaling factor to account for higher strain rates was obtained by curve fitting a set of data from a study [87] examining a 20 wt\% gelatin gel at two strain rates, $1 \mathrm{~s}^{-1}$ and $2500 \mathrm{~s}^{-1}$ (R-squared values approximately equal to 1 and 0.98 respectively), and was found to be 9.74. Extracting data from experimentation at strain rates of $2500 \mathrm{~s}^{-1}$ was considered acceptable due to the fact that properties for most materials are seen to plateau above certain strain rates. Samples were refrigerated at the recommended temperature of $4^{\circ} \mathrm{C}$ for 24 hours, subsequently removed, and allowed to equilibrate to a specific testing temperature before the experiments were carried out, set to be $20.5^{\circ} \mathrm{C}$. The temperature was adjusted and maintained through slow heating or cooling of the sample within a water bath.

\subsubsection{Experimental Setup}

Steel (diameter $=1.59 \mathrm{~mm}, 2.39 \mathrm{~mm}$, and $3.18 \mathrm{~mm}$ ), grade $5(6 \mathrm{Al} / \mathrm{V}$ ) high strength Titanium (diameter $=3.18 \mathrm{~mm})$, Polymethyl-methacrylate $($ diameter $=3.18 \mathrm{~mm}$ ), and Tungsten Carbide (diameter $=1.59 \mathrm{~mm}$ ) balls, a $60^{\circ}$ steel angular particle (side length $=6.0 \mathrm{~mm}$, thickness $=3.10 \mathrm{~mm}$ ), and a $45^{\circ}$ steel angular particle (side length $=5.83 \mathrm{~mm}$, thickness $=2.90 \mathrm{~mm}$ ) were accelerated to various velocities using a rectangular-bore gas gun [93] powered by compressed nitrogen, as depicted in Figure 3-6. A single particle was carried through the barrel in a Lexan sabot with a width, length and depth of $3.175 \mathrm{~mm}, 31.75 \mathrm{~mm}$, and $14.30 \mathrm{~mm}$, respectively, shown in Figure $3-7$, that had a sliding fit in the barrel which had a width and length of $3.2 \mathrm{~mm}$ and $31.8 \mathrm{~mm}$, respectively. A target holder held the gelatin target perpendicular to the flight path of the particle. This ensured an initial particle orientation of zero upon impact, ie., they were oriented as shown in the FE model for all cases. 


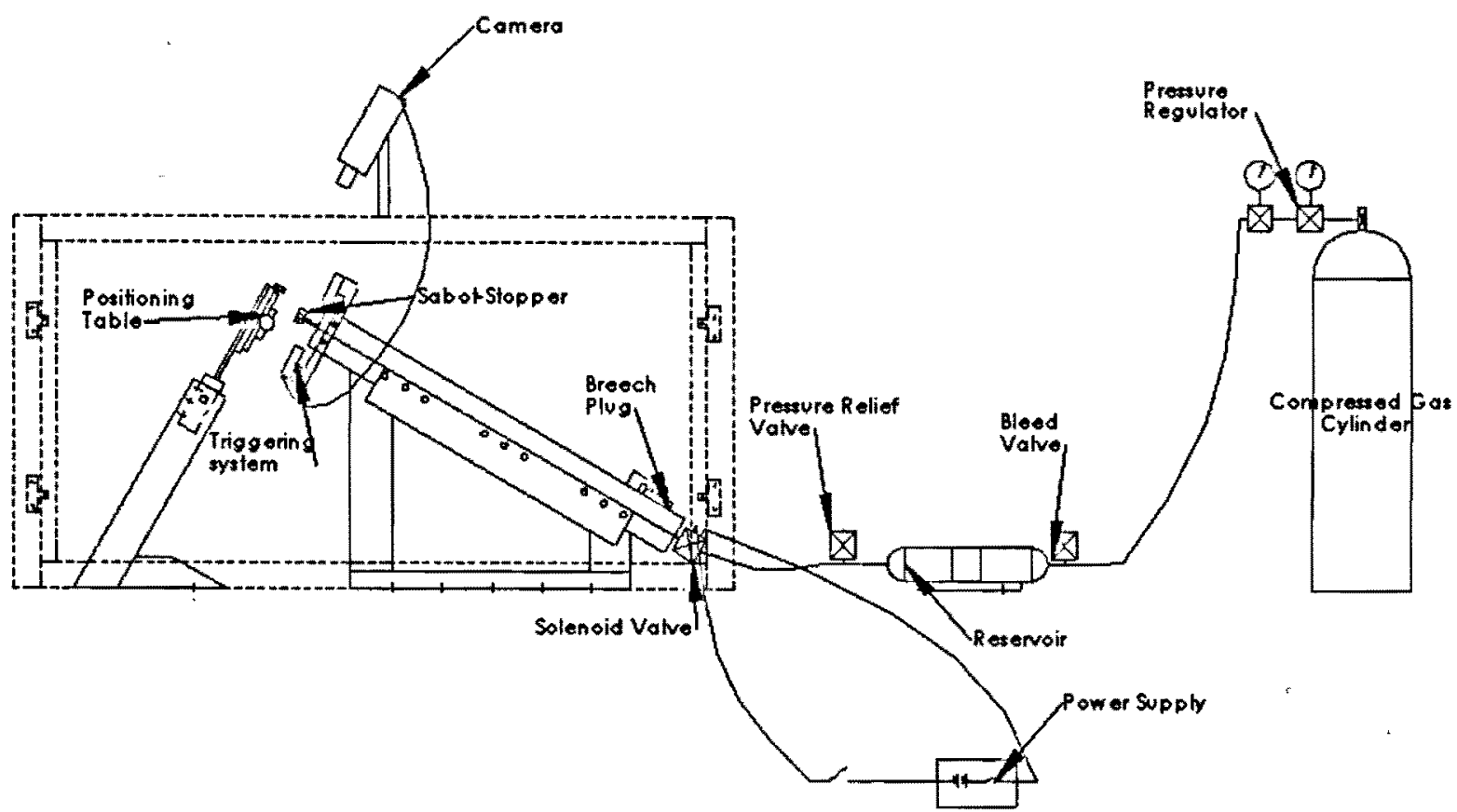

Figure 3-6: Schematic of experimental setup [93].

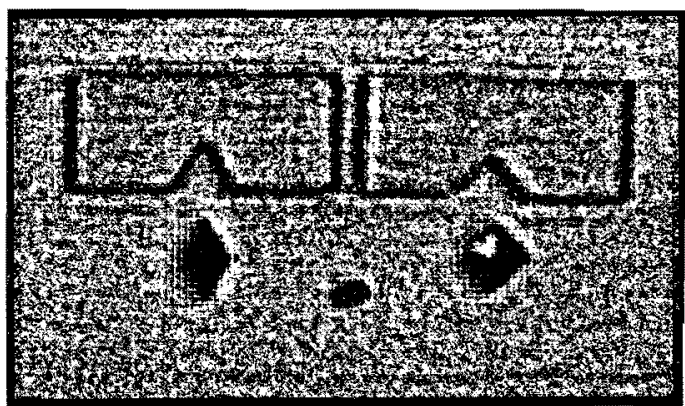

Figure 3-7: Sabots and particles employed with the gas gun in the gelatin experiments.

A FlashCAM high-speed digital camera (Cooke Corp., Auburn Hills, MI, USA), linked to a MultiTRIG (Cooke Corp.,Auburn Hills, MI, USA) infrared trigger and a video frame grabber, was used to obtain multiple exposures of the particles in flight at prearranged time intervals. An image analysis software was used to analyze the multiple exposures, and thus obtain the incident velocity, an example 
of which is shown in Figure 3-8 for the 3.18 diameter steel sphere and in Figure 3-9 for the $6.0 \mathrm{~mm}, 60^{\circ}$ angular particle. In the utilized configuration, the VGA resolution of the camera resulted in an uncertainty in the velocity measurement on the order of $2 \mathrm{~m} / \mathrm{s}$. Velocities at several different pressures for each ball and angular particle size were tested.

To measure the penetration depth, a wire was carefully inserted into the channel created by the impacting ball bearing and marked where it met the top of the gelatin surface. Upon removal from the gelatin, the penetration depth was measured on the wire using a digital vernier caliper. Figure 3-10 illustrates a typical sample with wire inserted for measurement. Each particular gelatin formulation was impacted five times to assess the reproducibility of the penetration depths.

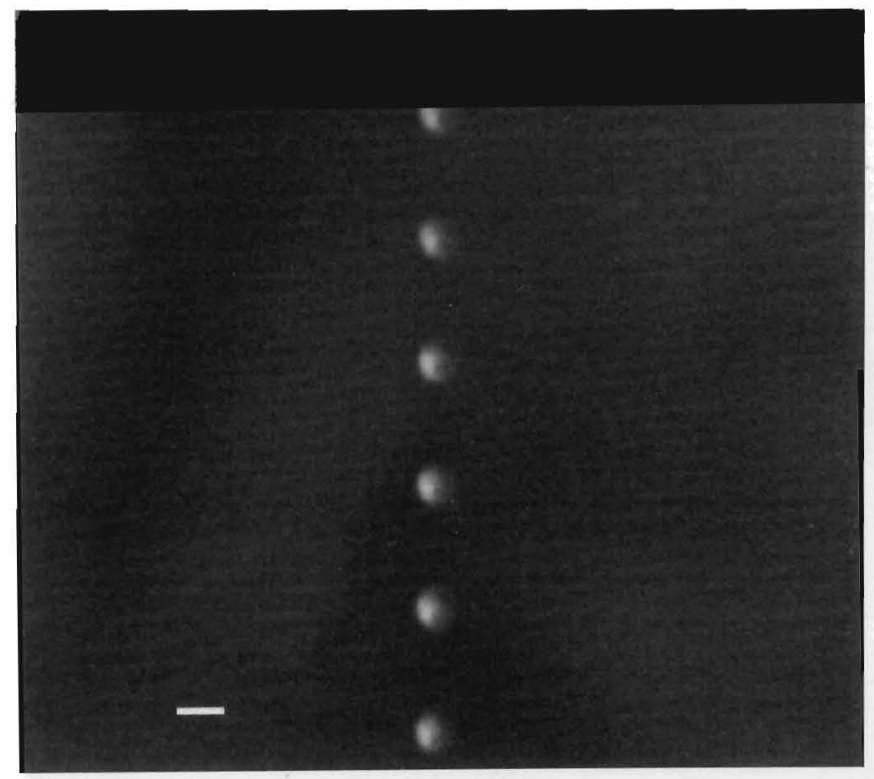

Figure 3-8: Multiple exposures of $3.18 \mathrm{~mm}$ steel ball in flight with the scaling bar representing $3.18 \mathrm{~mm}$. Nitrogen gas gun pressure $=\mathbf{4 0}$ psi; time delay of exposures was set to $220 \mu \mathrm{s}$. Measured distance between the exposures was $8.65 \mathrm{~mm}$, resulting in a measured speed of $39.3 \mathrm{~m} / \mathrm{s}$. 


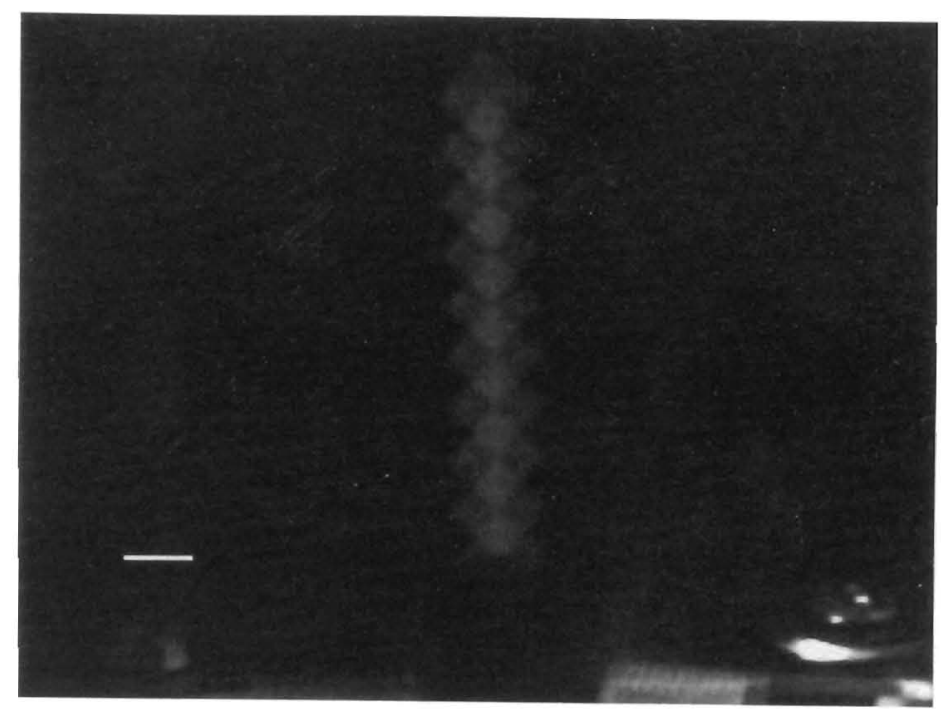

Figure 3-9: Multiple exposures of $6.0 \mathrm{~mm}, 60^{\circ}$ steel angular particle in flight with the scaling bar representing $6.0 \mathrm{~mm}$. Nitrogen gas gun pressure $=34 \mathrm{psi}$; time delay of exposures was set to $90 \mu \mathrm{s}$. Measured distance between the exposures was $5.64 \mathrm{~mm}$, resulting in a measured speed of $63 \mathrm{~m} / \mathrm{s}$.

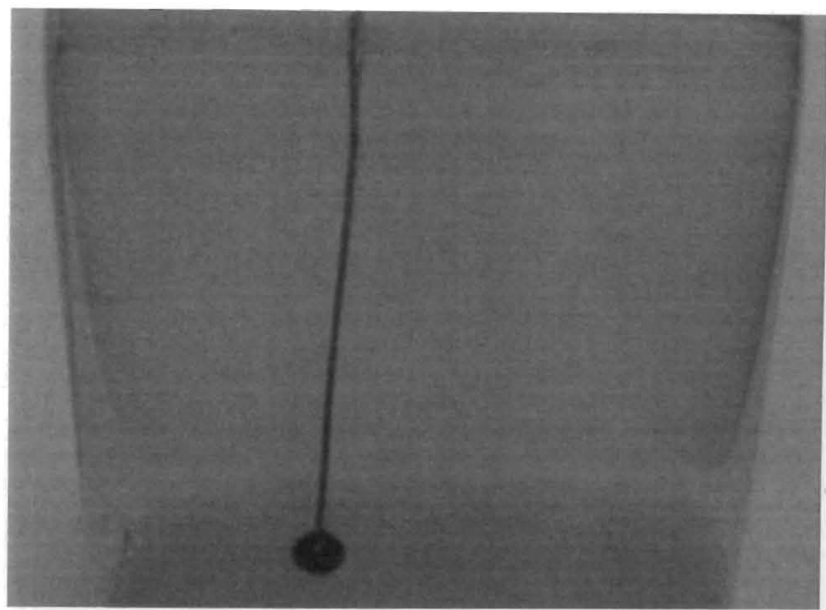

Figure 3-10: Gelatin sample with wire used to measure the particle penetration. 


\section{Chapter 4. Results and Discussion: Spherical Particles}

This chapter presents results and discussion relating to the FE modeling of the spherical particles, and the experimental results on the scaled up model steel ball-gelatin system. Section 4.1 .1 presents the list of possible material parameters that describe the behavior of skin, generated by the method detailed in Section 3.1.3. Section 4.1.2 describes the results of the initial gelatin-steel ball experiments and illustrates how the correct gelatin formulation can be selected using the dimensional analysis. Section 4.1.3 demonstrates how the correct material parameter combination from section 4.1 .1 can be selected.. Finally, experiments involving additional spherical particles of varying radius and density are presented in Section 4.1.4.

Section 4.2 discusses the developments that arise from the results of 4.1 . More specifically, Section 4.2.1 discusses the validity of the calculated elastic modulus for skin tissue, and Section 4.2.2 investigates the prediction power of the FE model developed from the calibration data by utilizing gold particles of varying diameter and velocity. The validity of gelatin as a model skin simulant is analyzed in Section 4.2 .3 by examining how particle characteristics such as size, density and velocity affect particle penetration depth, and whether these trends are the same as those found previously for skin in literature [33].

\subsection{Results}

\subsubsection{FE results - Estimation of material properties for calibration system}

As described in Section 3.1, the calibration system, i.e. the $2 \mu \mathrm{m}$ diameter gold $\left(\rho_{p}=16.8 \mathrm{~g} / \mathrm{cm}^{3}\right)$ particle launched at $651 \mathrm{~m} / \mathrm{s}$ against skin, resulted in a penetration of $26 \mu \mathrm{m}$ [24]. The results of the FE analysis that was used (Section 3.1.2) to obtain possible combinations of infinitesimal shear modulus, $\mu_{\infty}$, and failure strain that resulted in the $26 \mu \mathrm{m}$ penetration are shown in the first two columns of Table 
4-1. As the failure strain increased, a decrease in the corresponding infinitesimal shear modulus was required in order to maintain the target penetration.

For the corresponding scaled up model system, i.e., the $3.18 \mathrm{~mm}$ diameter steel $\left(\rho_{p}=7.8 \mathrm{~g} / \mathrm{cm}^{3}\right)$ ball bearing, launched at $83 \mathrm{~m} / \mathrm{s}$ against gelatin, the dimensionless groups of Section 3.2 imply that the model gelatin target density should be $0.464 \mathrm{~g} / \mathrm{cm}^{3}$, the systems should have equivalent strain hardening exponents, that the steel particle should penetrate $4.13 \mathrm{~cm}$ into the gelatin, and that:

$$
\mu_{\infty}^{\text {MODEL }}=0.00755 \mu_{\infty}^{\text {PROTOTYPE }}
$$

The contribution of the $\pi_{3}$ group was ignored because both the gold and steel particles have moduli that are three orders of magnitude larger than skin and gelatin and thus undergo negligible deformation upon impact [81]. The last column of Table 4-1 shows the calculated (using Equation 4-1) model system $\mu_{\infty}$ value that should theoretically result in a penetration of $4.13 \mathrm{~cm}$ for the steel sphere, if the calibration and model systems are to obey dimensional similtude.

Table 4-1: Possible calibration system shear modulus - erosion strain combinations required for a $26 \mu \mathrm{m}$ penetration of $2 \mu \mathrm{m}$ diameter gold particles into skin. The model system shear modulus given by equation 41, required for a $4.13 \mathrm{~cm}$ penetration of a $3.18 \mathrm{~mm}$ steel sphere into gelatin is shown in the third column.

\begin{tabular}{ccc}
\hline $\begin{array}{c}\text { Calibration } \mu_{\infty} \\
(\mathrm{MPa})\end{array}$ & $\begin{array}{c}\text { Erosion } \\
\text { strain }\end{array}$ & $\begin{array}{c}\text { Calculated model } \mu_{\infty} \\
(\mathrm{kPa})\end{array}$ \\
\hline 55 & 0.3 & 415 \\
32 & 0.4 & 242 \\
25 & 0.5 & 189 \\
20 & 0.6 & 151 \\
15 & 0.7 & 113 \\
10 & 0.8 & 76 \\
\hline
\end{tabular}




\subsubsection{Experimental results - Gelatin experiment}

Steel ball bearings were fired into several gels of varying weight percent gelatin using a velocity of $83 \mathrm{~m} / \mathrm{s}$. Table $4-2$ lists the penetration data for the each gel along with its corresponding high strain rate shear modulus value (Section 3.3.1). As the percentage gelatin, and thus the shear modulus, was increased, the penetration depth was found to decrease. The $12 \mathrm{wt} \%$ gel formulation resulted in a steel ball penetration of $4.05 \mathrm{~cm}$, which was within $2 \%$ of the desired $4.13 \mathrm{~cm}$. Thus, the $12 \mathrm{wt} \%$ gel formulation, which corresponded to a shear modulus value of $113 \mathrm{kPa}$, was used in all further experimentation.

Table 4-2: Gelatin concentration and penetration data for $3.18 \mathrm{~mm}$ diameter spheres performed five times

\begin{tabular}{cccc}
\hline $\begin{array}{c}\text { Gelatin } \\
\text { concentration } \\
(w+\%)\end{array}$ & $\begin{array}{c}\text { Shear modulus } \\
(\mathrm{kPa})\end{array}$ & $\begin{array}{c}\text { Average } \\
\text { Penetration }(\mathrm{cm})\end{array}$ & $\begin{array}{c}\text { Standard Deviation } \\
(\mathrm{cm})\end{array}$ \\
\hline 7 & 37 & 9.77 & 0.11 \\
8 & 55 & 8.56 & 0.13 \\
10 & 80 & 6.47 & 0.13 \\
12 & 113 & 4.05 & 0.21 \\
\hline
\end{tabular}

\subsubsection{FE results - Estimation of material properties for model system}

Using Equation 4-1, the skin shear modulus corresponding to the $12 \mathrm{wt} \%$ gelatin gel $\left(\mu_{\infty}=113\right.$ $\mathrm{kPa}$ ), is $15 \mathrm{MPa}$. Table 4-2 indicates that the skin erosion strain required to yield a skin penetration of 26 $\mu \mathrm{m}$ is approximately 0.7. Utilizing these values of erosion strain and the gel shear modulus value of 113 $\mathrm{kPa}$ into the model system FE analysis produced a penetration of $4.19 \mathrm{~cm}$. The low difference of $1.45 \%$ 
between the FE penetration and that predicted by the dimensional analysis confirms the validity of the analysis.

\subsubsection{Experimental results - Additional gelatin experiments}

The results of additional penetration experiments using balls of varying densities and sizes with several different impact velocities on the 12 wt\% gelatin formulation are shown in Table 4-3. The experimental results are compared to those found in skin in Section 4.2.3.

\subsection{Discussion}

\subsubsection{Elastic modulus of skin}

The gelatin shear modulus value found to generate a penetration closest to the $4.13 \mathrm{~cm}$ required to produce dimensional similitude between the model and calibration systems was $113 \mathrm{kPa}$, corresponding to a skin modulus of approximately $15 \mathrm{MPa}$. This high-strain rate infinitesimal shear modulus can be converted to a quasi-static shear modulus value by employing a scaling factor of 20 , found by Shergold and Fleck [63] through the testing of pig skin, yielding a value of $0.75 \mathrm{MPa}$. The elastic modulus, $E$, may be subsequently obtained by assuming a condition of incompressibility whereby the two moduli values are related by $E=3 \mu_{\infty}$, yielding $E=2.25 \mathrm{MPa}[63]$.

The quasi-static value of $E=2.25 \mathrm{MPa}$ estimated using the present approach agrees reasonably well with values for skin established using various testing methods. The range of moduli found in the literature is between $0.02 \mathrm{MPa}$ and $57 \mathrm{MPa}$ [61], depending on the testing method and location where the measurement is made. For example, a range of 1.1-1.32 MPa was found utilizing a disc of $18 \mathrm{~mm}$ diameter and guard ring of $24 \mathrm{~mm}$ in torsion on the anterior side of the human forearm [94], while Kendall et al. [58] found a modulus value of $3.75 \mathrm{MPa}$ while indenting murine ear with a $5 \mu \mathrm{m}$ 
Table 4-3: Penetration results for balls characterized by varying sizes, densities, and impact velocities

\begin{tabular}{|c|c|c|c|c|}
\hline $\begin{array}{c}\text { Ball } \\
\text { material }\end{array}$ & $\begin{array}{l}\text { Density } \\
\left(\mathrm{kg} / \mathrm{m}^{3}\right)\end{array}$ & $\begin{array}{l}\text { Diameter } \\
\text { (mm) }\end{array}$ & $\begin{array}{l}\text { Velocity } \\
(\mathrm{m} / \mathrm{s})\end{array}$ & $\begin{array}{c}\text { Experimental } \\
\text { Penetration }(\mathrm{cm})\end{array}$ \\
\hline Steel & 7800 & 1.59 & 45 & 1.83 \\
\hline Steel & 7800 & 1.59 & 72 & 3.76 \\
\hline Steel & 7800 & 1.59 & 83 & 4.04 \\
\hline Steel & 7800 & 1.59 & 98 & 5.05 \\
\hline Steel & 7800 & 2.39 & 93 & 3.45 \\
\hline Steel & 7800 & 2.39 & 101 & 3.87 \\
\hline Steel & 7800 & 2.39 & 107 & 4.18 \\
\hline Steel & 7800 & 2.39 & 115 & 4.46 \\
\hline Steel & 7800 & 1.59 & 85 & 1.92 \\
\hline Steel & 7800 & 1.59 & 95 & 2.12 \\
\hline Steel & 7800 & 1.59 & 102 & 2.46 \\
\hline Steel & 7800 & 1.59 & 112 & 2.76 \\
\hline $\mathrm{Ti}$ & 4540 & 3.18 & 59 & 1.62 \\
\hline $\mathrm{Ti}$ & 4540 & 3.18 & 71 & 2.67 \\
\hline $\mathrm{Ti}$ & 4540 & 3.18 & 85 & 3.31 \\
\hline $\mathrm{Ti}$ & 4540 & 3.18 & 95 & 3.79 \\
\hline WC & 15600 & 1.59 & 52 & 2.31 \\
\hline WC & 15600 & 1.59 & 66 & 3.18 \\
\hline$W C$ & 15600 & 1.59 & 78 & 3.92 \\
\hline WC & 15600 & 1.59 & 88 & 4.07 \\
\hline PMMA & 1150 & 3.18 & 80 & 0.53 \\
\hline PMMA & 1150 & 3.18 & 88 & 0.63 \\
\hline PMMA & 1150 & 3.18 & 99 & 0.88 \\
\hline PMMA & 1150 & 3.18 & 109 & 0.96 \\
\hline
\end{tabular}


microneedle. Furthermore, the critical strain value utilized in order to obtain the desired penetration with the FE models $(0.7)$ falls within the range listed for pig skin (commonly used to simulate human skin), given by $0.00-1.00$, with a median ranging $0.3-0.55$, depending on the direction tested [90]. As previously mentioned, the median values found by testing pig skin are slightly higher than values found in literature for human skin at moderate to high strain rates [91, 92].

\subsubsection{Particle penetration trends using FE}

As an additional test of the validity, the modulus value and erosion strain were employed in the calibration FE model using varying gold particle sizes and velocities to produce a wide variation in the particle impact parameter, pva, used by Kendall et al. [24] in experiments on epidermal tissue using the powder injection device. Figure 4-1 shows that the FE predictions of particle penetration agree well with the experimental results of Kendall et al. [24], always falling within the one standard deviation experimental scatter bars. The general trend of increasing penetration with increasing $\rho v a$ values for a particle of particular size and density was also captured by the model, as was the trend of larger particles requiring a larger $\rho v a$ value to penetrate to a given depth.

\subsubsection{Gelatin as a skin simulant}

The use of dimensional analysis as a comparative tool between the real skin system and the chosen simulant system has proven to be useful in the examination of the skin's mechanical behaviour in the application of powder injection. Figure 4-2 depicts the measured penetration results with respect to the particle impact parameter of the gelatin experiments carried out using the steel, titanium, PMMA and tungsten carbide balls of varying diameters and velocities. Similar to the results for gold and polystyrene particles found by Mitchell et al. [33] in their studies of microparticle impact with fresh canine and porcine buccal mucosa (cheek) using a contoured shock tube and light gas gun developed for the purpose of their study, the penetration depth increases with the particle impact parameter can. It is 


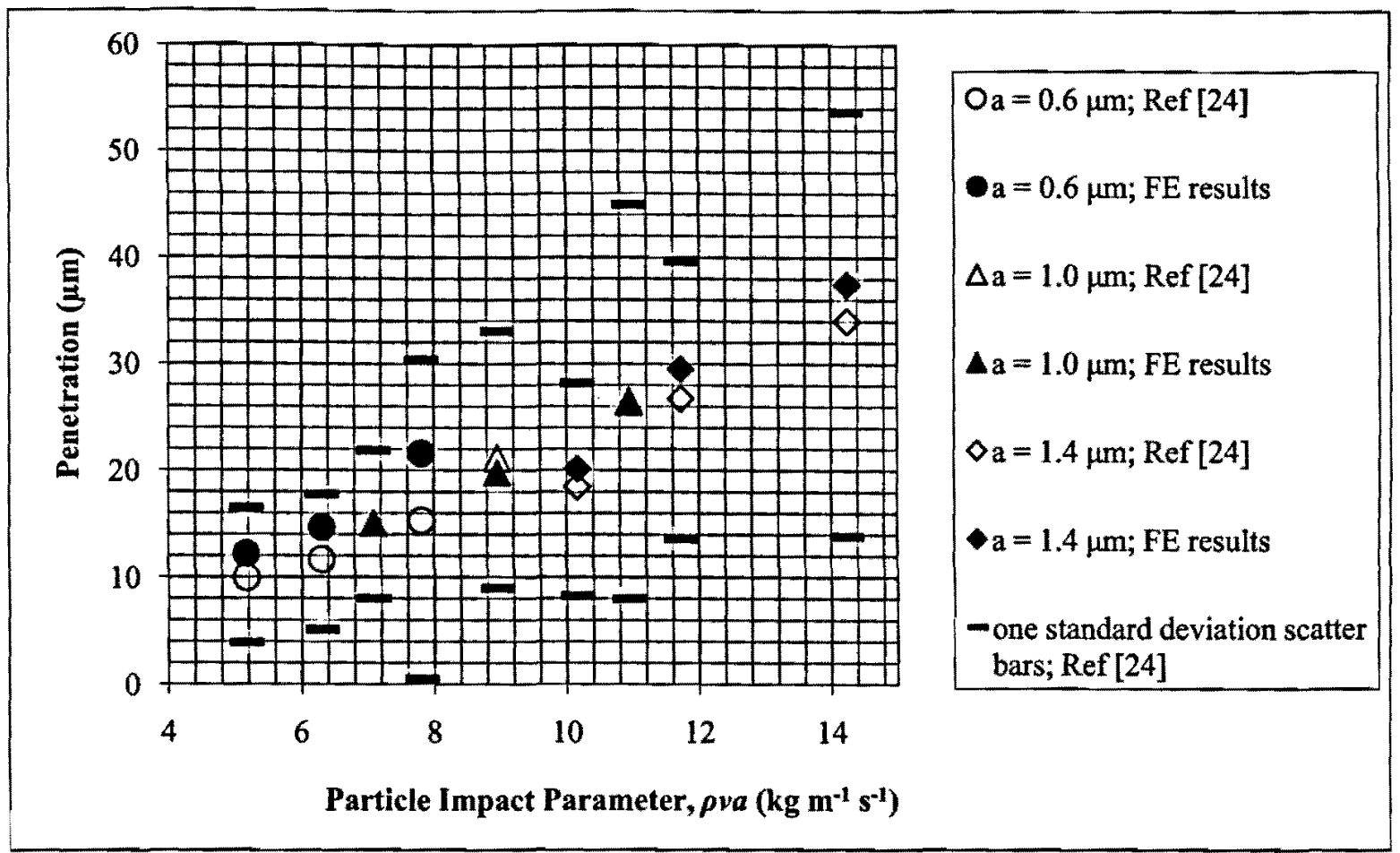

Figure 4-1: Gold particle impact parameter versus skin penetration depth for various particle sizes. Data from literature [24] and FE results.

apparent that an increase in velocity, and hence incident energy, causes an increase in penetration depth, as expected.

The data presented in Figure 4-2 are replotted in Figure 4-3 using the non-dimensional penetration and a non-dimensional impact energy. It is interesting to note that although the data do not all fall on the same line, the lines of best fit belonging to each set of data have similar slopes; all the particles follow the same trend in non-dimensional penetration with respect to the nondimensional energy parameter.

\subsubsection{Effect of particle size on penetration depth}

The effect of particle size on penetration depth may be visualized more clearly by examining the three steel balls impacting with the same incident velocity. Although the velocities tested for each ball 
were different, penetrations for one unified velocity was possible by using the equation for the linear curve fit, shown in Figure 4-2. The penetrations for the steel balls, each having an impact velocity of 100 $\mathrm{m} / \mathrm{s}$, are plotted with respect to radius in Figure 4-4. A clear trend of increasing penetration depth with increasing particle radius can be seen. This was also demonstrated using gold balls of varying diameter by Mitchell et al. [33].

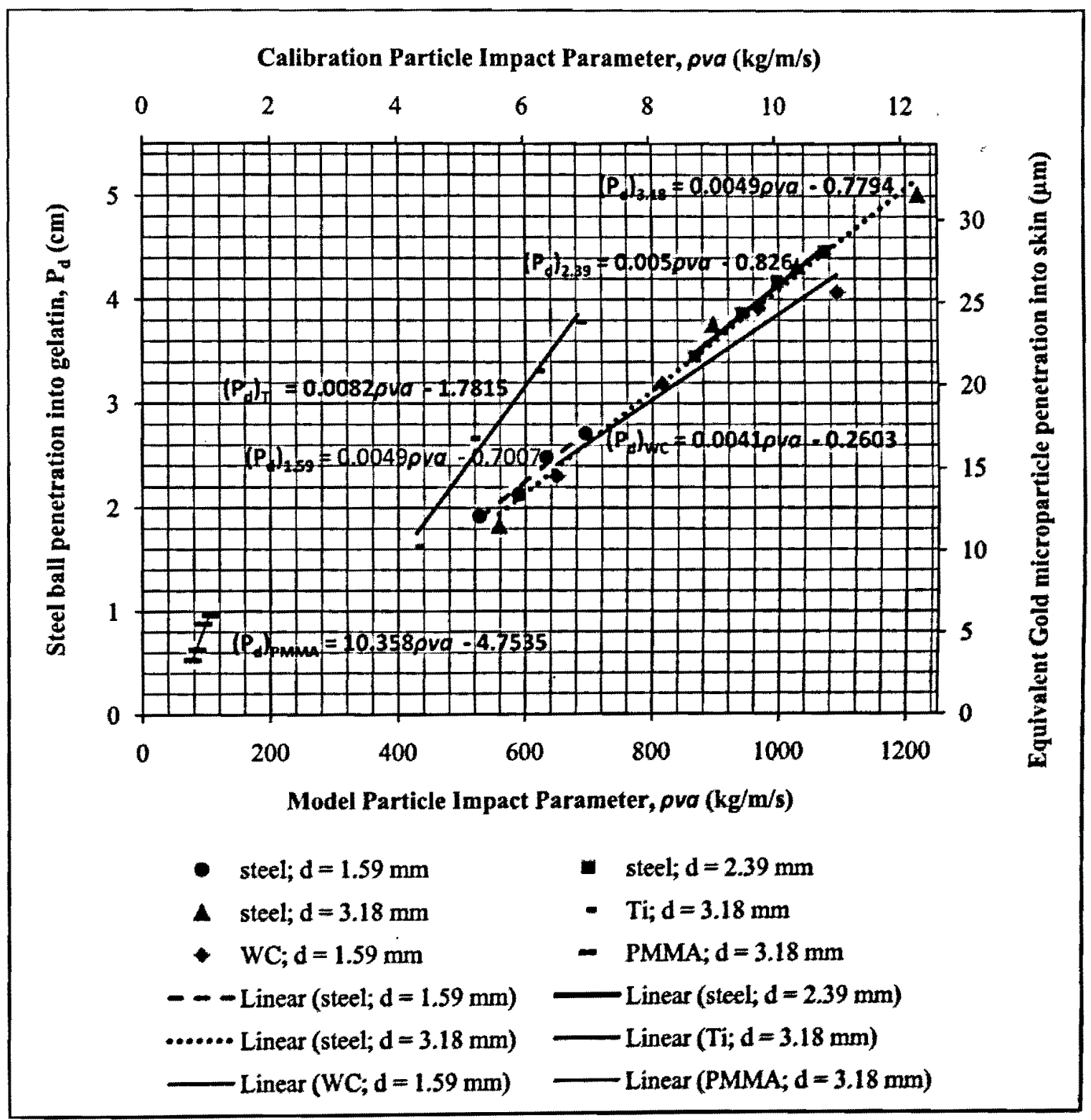

Figure 4-2: Gelatin experiments using steel balls of varying sizes and velocities; data is plotted with linear trendlines with equations given with respect to the primary axis. Secondary horizontal (top) and vertical (right) axes examine particle impact parameters and penetration of equivalent microparticles on skin. 


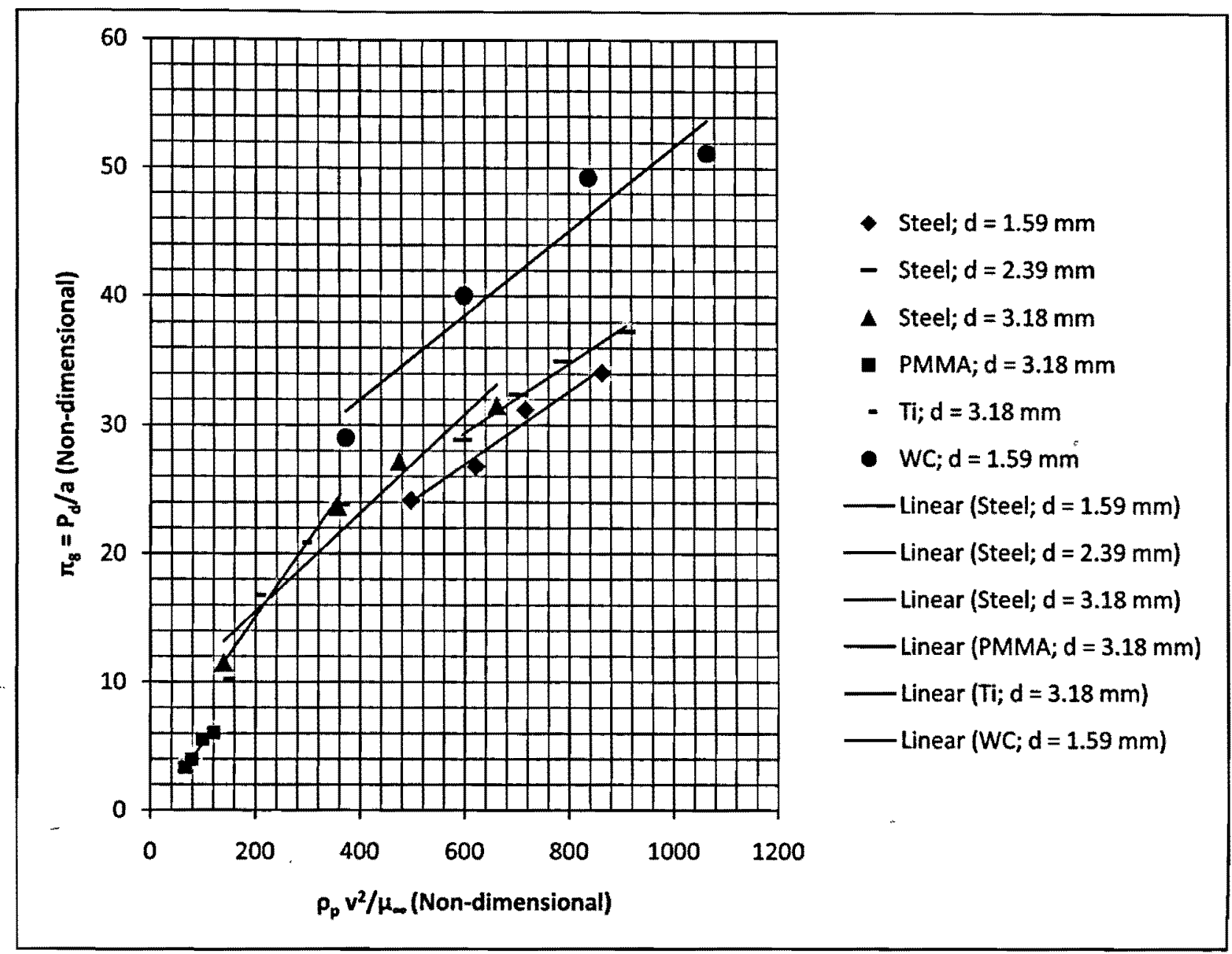

Figure 4-3: Gelatin experiments using steel, titanium, PMMA, and tungsten carbide balls of varying sizes and velocities plotted using non-dimensional parameters. Data is plotted with linear trendlines.

\subsubsection{Effect of particle density on penetration depth}

The effect of particle density on penetration depth was examined by plotting density versus dimensionless penetration parameter, $P_{d} / 2 a$ which is equivalent to the number of particle diameters penetrated by each particle, as suggested by Mitchell et al. [33]. In this way, it was possible to compare data from differently sized particles impacting with the same nominal velocity. Figure 4-5 illustrates that 
the dimensionless penetration, or number of penetrated particles, will increase with density, which agrees with the results found in Ref. [33].

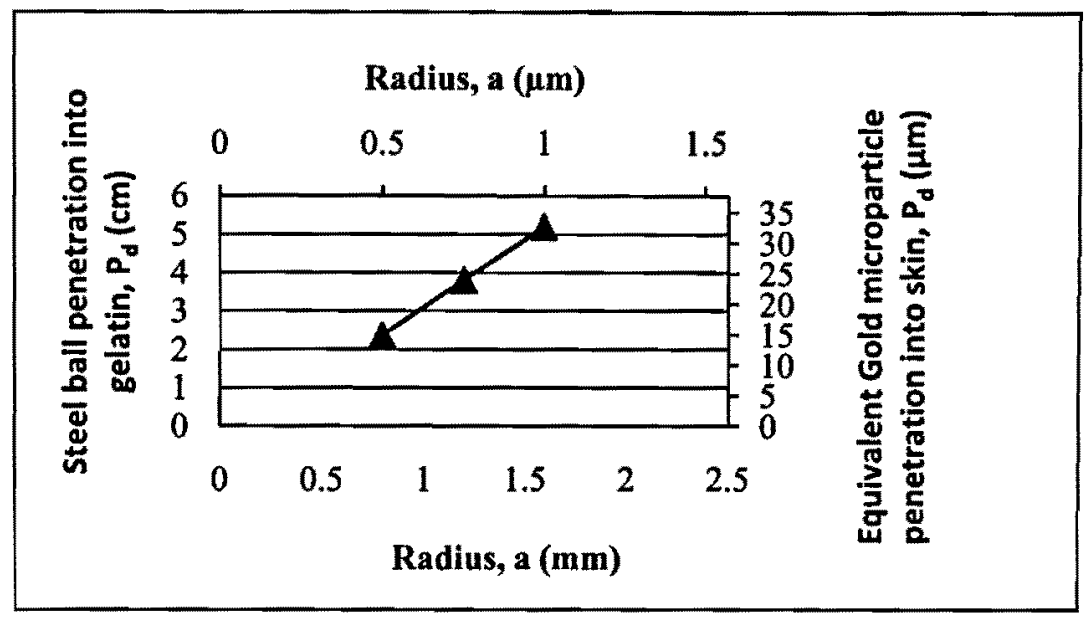

Figure 4-4: Penetrations for steel balls of diameters $1.59 \mathrm{~mm}, 2.39 \mathrm{~mm}$, and $3.18 \mathrm{~mm}$ with impact velocities of $100 \mathrm{~m} / \mathrm{s}$ plotted with a linear trendline. Secondary horizontal and vertical axes examine particle impact parameters and penetration of equivalent microparticles on skin.

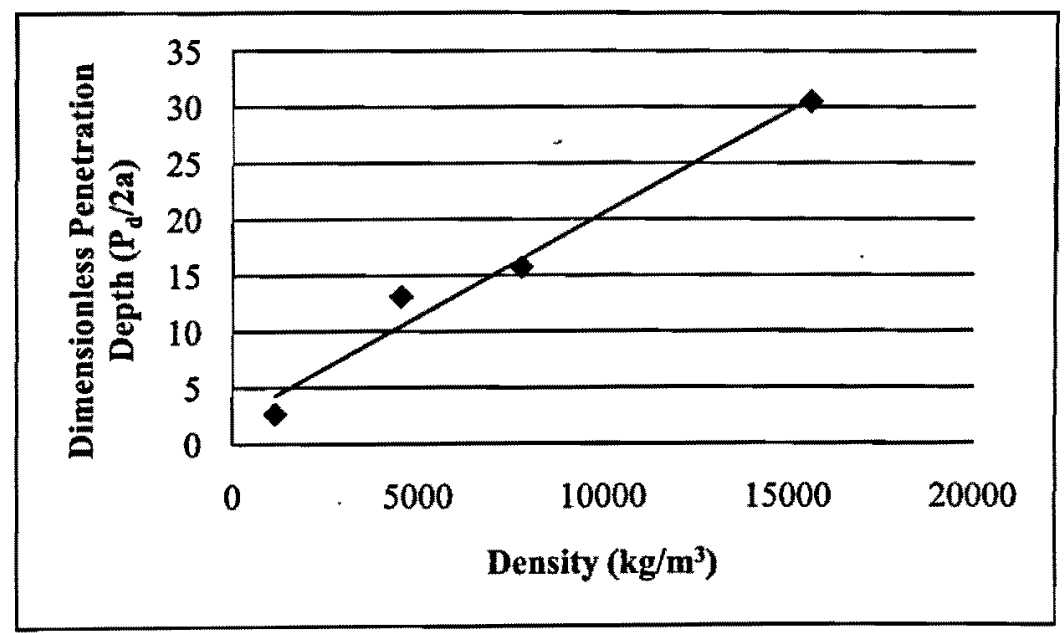

Figure 4-5: Effect of particle density on penetration depth for a velocity of $100 \mathrm{~m} / \mathrm{s}$ using PMMA, titanium, steel, and tungsten carbide balls plotted with a linear trendline. 


\subsubsection{Effect of particle impact velocity on penetration depth}

The effect of impact velocity on penetration was analyzed using another dimensionless parameter suggested by Mitchell et al. [33], which relates the particle's ultimate displacement to the particle's size and density, and the skin's density. Figure 4-6 depicts the relationship between the particle velocity and the previously mentioned dimensionless parameter for the steel, titanium, PMMA, and tungsten carbide balls at several impact velocities. The average of the grouped data is also shown in Figure 4-6 and highlights the trend of an increase in the non-dimensional penetration of a given particle as its impact velocity is increased. This has also been demonstrated by Mitchell et al. [33].

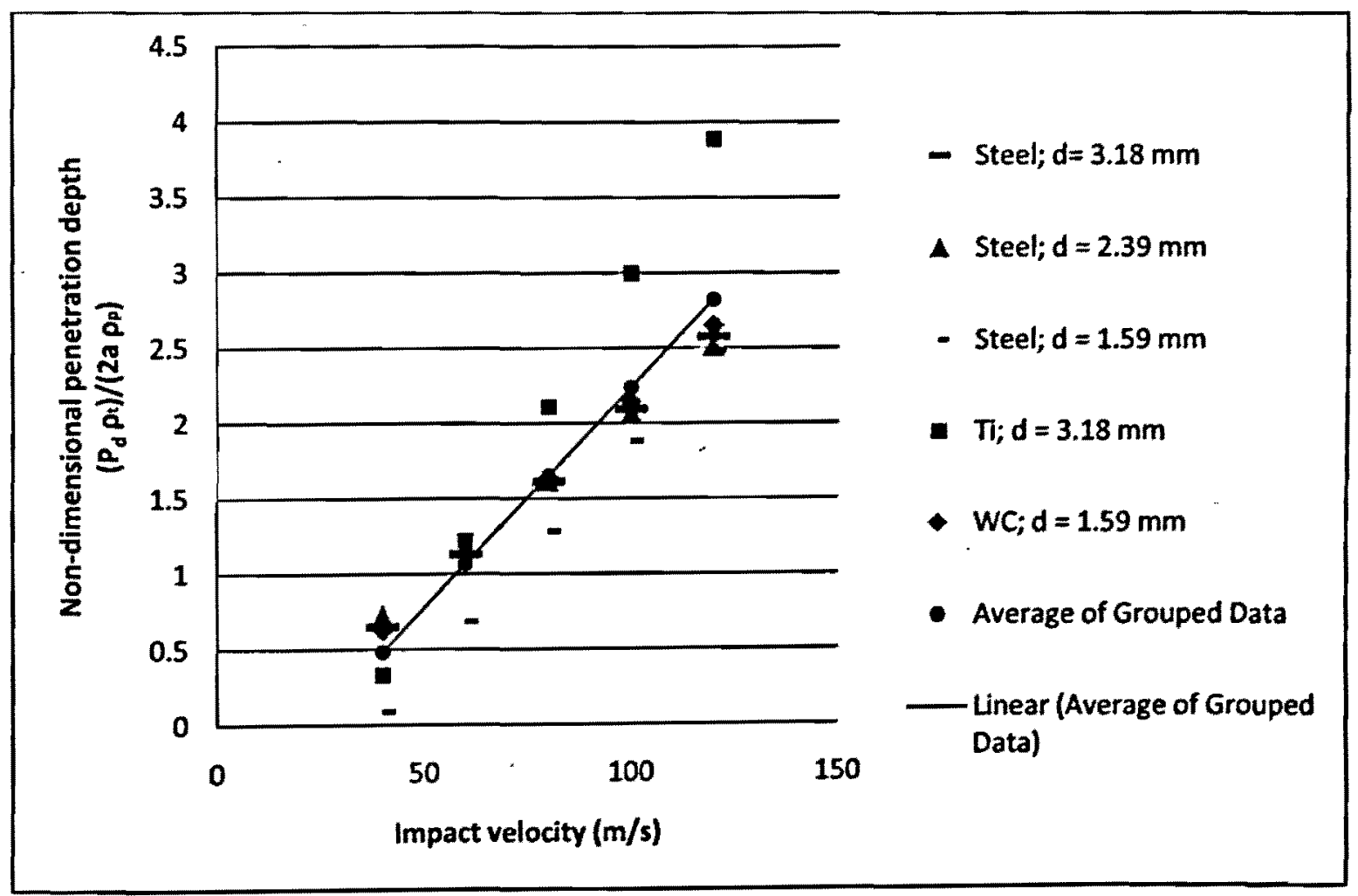

Figure 4-6: Effect of velocity on penetration. 


\subsubsection{Use of gelatin system to predict penetration depth in skin}

A further test of the use of gelatin as a skin simulant can be obtained by applying the scaling relations given by $\pi_{4}$ and $\pi_{8}$ (Table 3-2) to relate the experimentally measured $3.18 \mathrm{~mm}$ diameter steel ball penetration to all of the original collated data in Kendall et al. [24], i.e., the three gold particle sizes impacting at three different velocities. In other words, the experimentally-obtained steel ball-gelatin data were converted to equivalent gold particle penetrations in skin and then compared to the actual gold particle-skin penetration data in order to determine their prediction power for impact conditions that differ from the calibration test case $\left(r=1 \mu \mathrm{m}, v=651 \mathrm{~m} / \mathrm{s}, P_{d}=26 \mu \mathrm{m}\right)$ using the following procedure:

$\pi_{4}=\frac{\rho_{t} v^{2}}{\mu_{\infty}}$ was used to relate each case of the gold particle penetrations to the $3.18 \mathrm{~mm}$ steel ball case, giving the velocity required by the steel ball in order for the two systems to be equivalent. This velocity was used to obtain the steel ball penetration using the linear curve fit of Figure $4-2, P_{d}=$ $0.0049^{*} \rho v a-0.7794$, and then the equivalent gold particle penetration was found using $\pi_{8}=\frac{P_{d}}{a}$. Figure 4-7 shows the equivalent penetrations obtained using the gelatin system from the curve fit of Figure 4-2, together with the gold particle penetrations from Ref. [24].

Table 4-4 lists the average difference in measured [24] and predicted penetrations for the same gold particle penetrations obtained by scaling the steel ball experimental (Figure 4-2) and FE results (Figure 41). The differences between the expected and measured penetrations were low, providing further confidence in the suitability of gelatin to simulate the penetration behaviour of skin. In addition, the average percentage difference found using the experimental penetrations was slightly lower than those found using the FE model. 


\subsubsection{Limitations of the approach}

Finding a model system with the ability to fulfill all of the dimensional requirements was difficult.

Dimensional similitude of fourth dimensional group, $\pi_{4}=\frac{\rho_{t} v^{2}}{\mu_{\infty}}$, relating the target moduli and

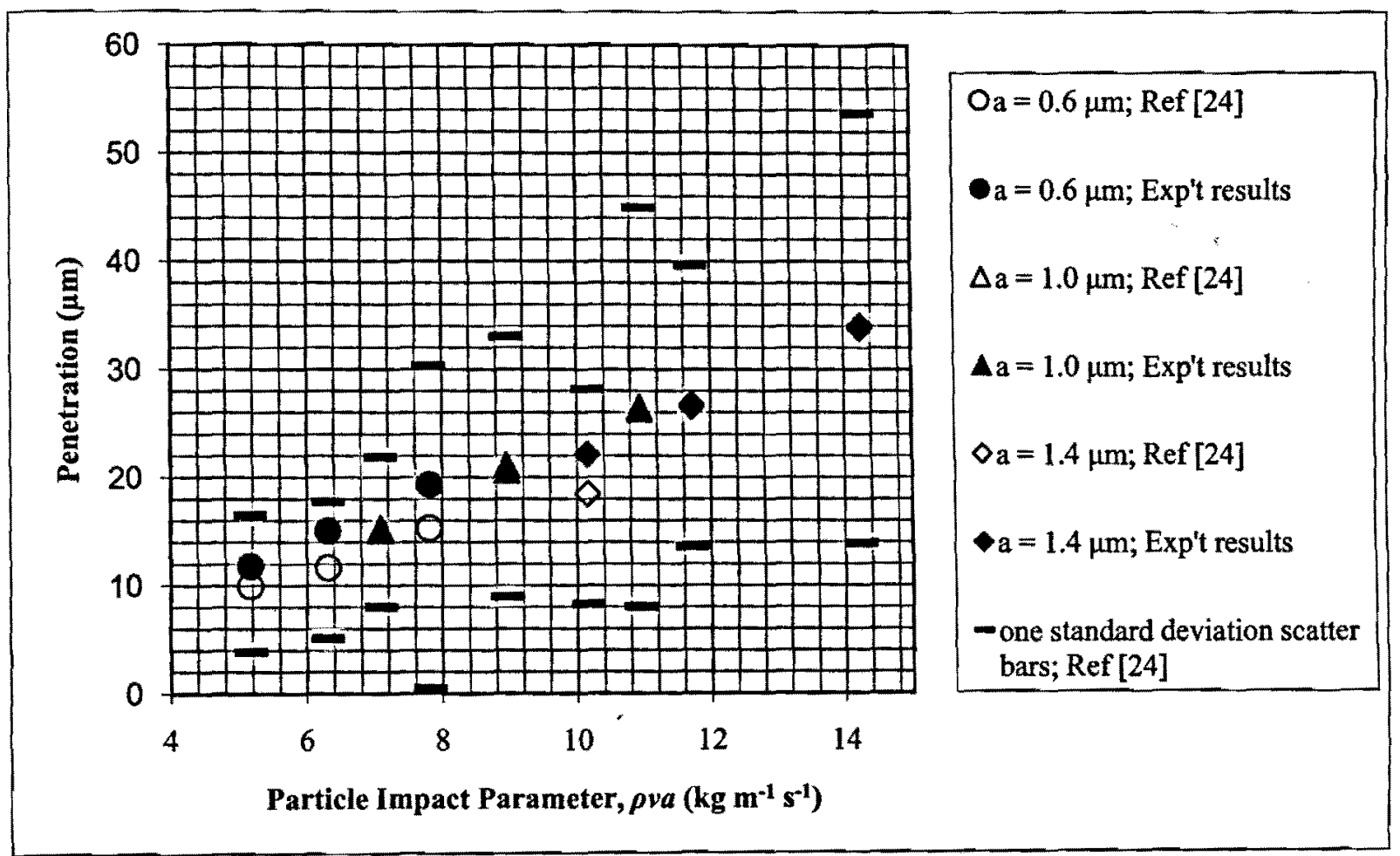

Figure 4-7: Particle impact parameter versus penetration depth for various particle sizes; data from literature [24] and linear extrapolation of experimental results.

densities, was particularly difficult to maintain. The gelatin used in this study had a higher density (1.01 $\mathrm{g} / \mathrm{cm}^{3}$ ) than the value of $0.464 \mathrm{~g} / \mathrm{cm}^{3}$ required by dimensional similitude. It was important to use the dimensionally similar value in the FE model of the gelatin-system, but the measured penetrations were insensitive to the target density. This discrepancy may be explained by the difference between simulated erosion strain and real crack propagation. In reality, inertial effects are only important initially when the target surface is first accelerated to the speed of the particle, after which a crack 
(approximated by eroding elements in the FE model) forms ahead of the impacting particle and propagates largely independent of any inertial effects. However, in the case of the FE model, the crack propagation is simulated with element deletion and each element in contact or adjacent to the impacting particle must be accelerated to the particle's speed in order to reach the critical element

Table 4-4: Absolute percentage difference between the equivalent gold particle penetrations found by experimentally and $\mathrm{FE}$ determined steel ball penetrations and the original gold particle penetration data.

\begin{tabular}{|c|c|c|c|c|c|c|}
\hline $\begin{array}{l}\text { Particle } \\
\text { radius } \\
\text { ( } \mu \mathrm{m})\end{array}$ & $\begin{array}{c}\text { Velocity } \\
(\mathrm{m} / \mathrm{s})\end{array}$ & $\begin{array}{c}\text { Original gold } \\
\text { particle-skin } P_{d} \\
(\mu \mathrm{m})\end{array}$ & $\begin{array}{c}\text { Experimentally } \\
\text { obtained } \\
\text { equivalent } P_{\mathrm{d}}(\mu \mathrm{m})\end{array}$ & $\begin{array}{l}\text { FE obtained } \\
\text { equivalent } P_{d} \\
(\mu \mathrm{m})\end{array}$ & $\begin{array}{l}\text { Percent error in } \\
\text { experimental } P_{d}\end{array}$ & $\begin{array}{l}\text { Percent error } \\
\text { in FE } P_{d}\end{array}$ \\
\hline \multirow{3}{*}{$r=0.6$} & 513 & 9.97 & 11.81 & 12.19 & 18.5 & 22.32 \\
\hline & 626 & 11.67 & 15.05 & 14.68 & 29 & 25.83 \\
\hline & 775 & 15.31 & 19.34 & 21.61 & 26.3 & 41.13 \\
\hline \multirow{3}{*}{$r=1.0$} & 422 & 15.07 & 15.32 & 15.07 & 1.65 & 0.004 \\
\hline & 533 & 21.15 & 20.64 & 19.82 & 2.41 & 6.27 \\
\hline & 651 & 26.49 & 26.29 & 26.39 & 0.77 & 0.39 \\
\hline \multirow{3}{*}{$r=1.4$} & 432 & 18.47 & 22.12 & 20.14 & 19.7 & 9.03 \\
\hline & 498 & 26.74 & 26.54 & 29.5 & 0.72 & 10.34 \\
\hline & 606 & 34.03 & 33.79 & 37.46 & 0.71 & 10.09 \\
\hline \multicolumn{3}{|c|}{ Average percent difference } & & & 11.08 & 13.93 \\
\hline
\end{tabular}

deletion strain. Similarly, maintaining similitude of the third dimensional group, $\pi_{3}=\frac{\rho_{p} v^{2}}{E}$, of the two systems was ignored since, regardless of material, the particle modulus was always much larger than the target modulus. 
The approximation of skin as a single homogeneous layer within the finite element model utilized in this study introduced several limitations. There is a relatively large difference in moduli values of the viable epidermis and the stratum corneum. Within this body of work, the relative contribution of each layer was not considered, meaning that it cannot provide information about the critical particle and process parameters necessary to breach only the stratum corneum layer. However, it is able to predict the skin's overall response under certain test conditions. The model is also limited in its ability to account for varying external aspects that may cause a change in the skin's mechanics. The factors found to affect the ballistic delivery of powdered pharmaceuticals, are largely predominated by ambient temperature and relative humidity [37]. The generated FE model represents only one set of these test conditions and the simulation of other conditions would require the formulation of different gelatin formulations, utilizing the same method detailed in this thesis. 


\section{Chapter 5. Results and Discussion: Angular Particles}

This chapter presents results and discussion relating to the FE modeling and experimental results for the angular particles used in this study. Section 5.1.1 presents the two erosion strain criteria found to adequately describe the behavior of the square and $60^{\circ}$ angular particles. It also shows the experimental penetrations observed for both particles, while Section 5.1 .2 details the FE penetration results. Section 5.2.1 compares the FE results to the experimental results and discusses whether the FE models are able to accurately represent the experiments involving the steel angular particle-gelatin system. Section 5.2.2 concludes with an analysis of the effect of angularity on penetration depth by contrasting the penetration results of the $60^{\circ}$ angular particle at a particular velocity to that of a square and a sphere having the same mass and initial velocity.

\subsection{Results}

\subsubsection{Experimental results}

Two different angular particles made of steel were each tested using six different velocities. The penetration results for all these particles are listed in Table 5-1 along with the particle's angularity, mass and incident velocity.

\subsubsection{Comparison of FE to experimental results}

The erosion strain used in FE models is a nonphysical parameter that is highly dependent on the scenario being examined, as discussed in detail in [93]. Thus, for the finite element models examining the impact of angular particles, the erosion strain was treated as a free parameter and adjusted such that the model was able to predict a single calibration impact event characterized by a unique velocity. This erosion strain and the infinitesimal shear modulus obtained for the $12 \mathrm{wt} \%$ gelatin formulation in 
Table 5-1: Penetration data for angular particles.

\begin{tabular}{|c|c|c|c|}
\hline $\begin{array}{l}\text { Particle } \\
\text { Angularity }\end{array}$ & $\begin{array}{c}\text { Mass } \\
\text { (g) }\end{array}$ & $\begin{array}{c}\text { Velocity } \\
\text { (m/s) }\end{array}$ & $\begin{array}{c}\text { Penetration } \\
\text { (cm) }\end{array}$ \\
\hline 60 & 0.7027 & 25 & 1.69 \\
\hline 60 & 0.7027 & 30 & 2.37 \\
\hline 60 & 0.7027 & 33 & 2.66 \\
\hline 60 & 0.7027 & 40 & 3.44 \\
\hline 60 & 0.7027 & 48 & 4.36 \\
\hline 60 & 0.7027 & 55 & 4.98 \\
\hline 45 & 0.7509 & 35 & 1.65 \\
\hline 45 & 0.7509 & 45 & 2.87 \\
\hline 45 & 0.7509 & 47 & 3.22 \\
\hline 45 & 0.7509 & 50 & 3.89 \\
\hline 45 & 0.7509 & 55 & 4.28 \\
\hline 45 & 0.7509 & 60 & 4.84 \\
\hline
\end{tabular}

Section 3.3.1, were used in subsequent simulations for the same particle. For the $60^{\circ}$ steel angular particle, the experimental conditions for this calibration event were: impact velocity of $40 \mathrm{~m} / \mathrm{s}$, resulting in a penetration of $3.44 \mathrm{~cm}$, while for the $45^{\circ}$ steel angular particle, the experimental conditions used were: impact velocity of $50 \mathrm{~m} / \mathrm{s}$, resulting in a penetration of $3.89 \mathrm{~cm}$. The erosion strains found in this manner were 0.975 for the $60^{\circ}$ steel angular particle, and 0.51 for the $5.83 \mathrm{~mm} 45^{\circ}$ steel angular particle, differing slightly from the value of 0.7 found in the case of the spherical particles. Figure 5-1 presents the $\mathrm{FE}$ and experimental results for the $60^{\circ}$ angular particle while the results for the $45^{\circ}$ angular particle are shown in Figure 5-2. 


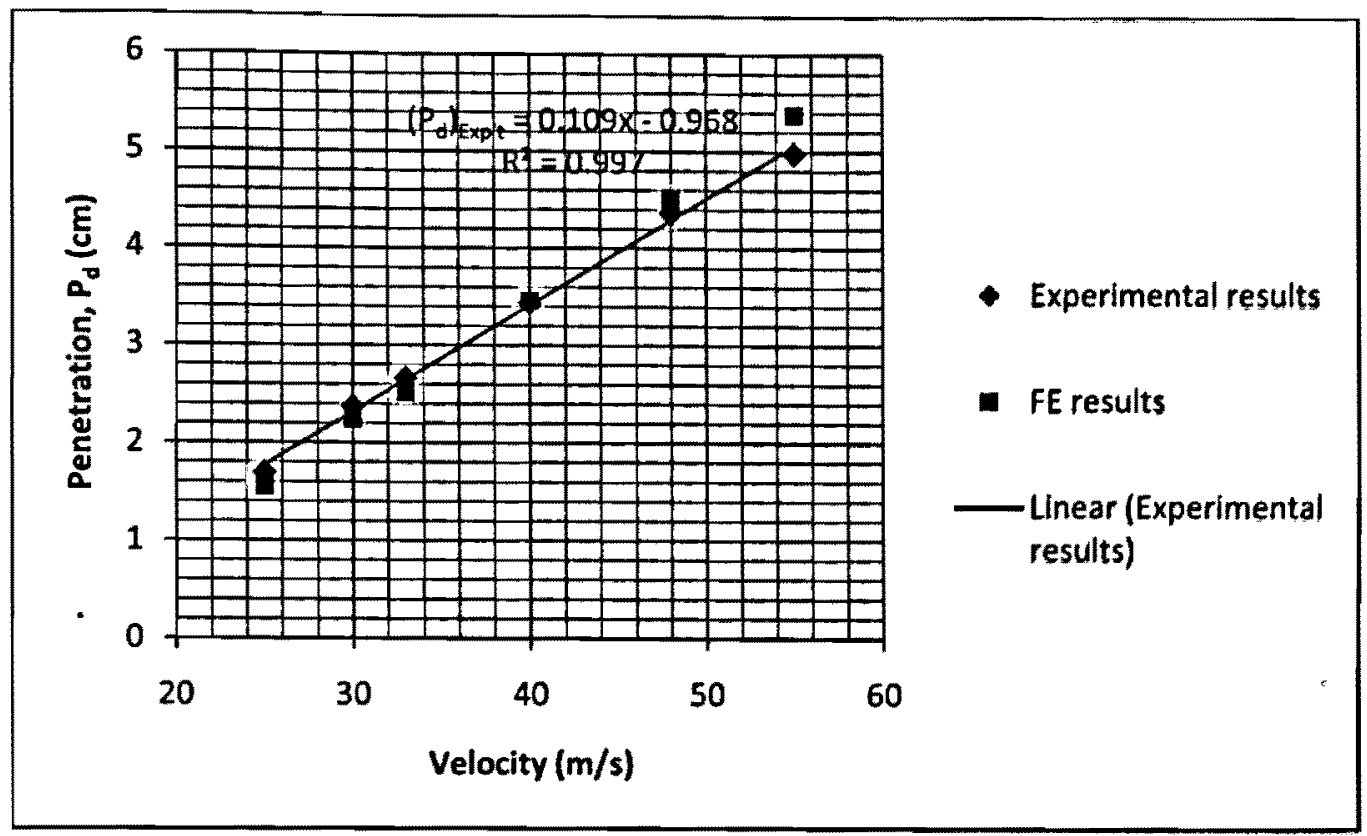

Figure 5-1: Penetration results for the particle with an angularity of $60^{\circ}$ over a range of velocities along with a linear curve fit.

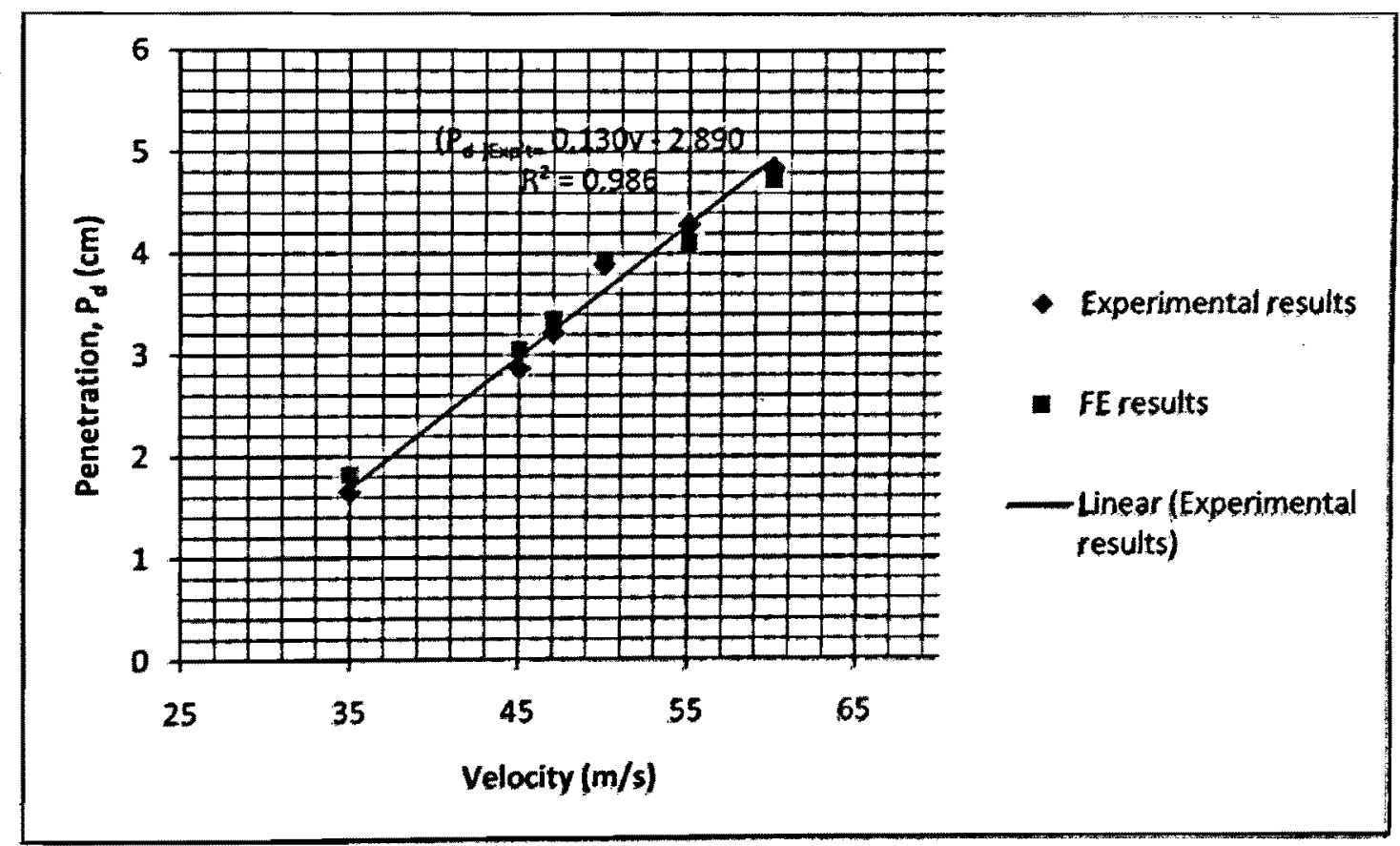

Figure 5-2: Penetration results for the particle with an angularity of $45^{\circ}$ oyer a range of velocities along with a linear curve fit. 


\subsection{Discussion}

\subsubsection{FE model prediction power}

The results presented in Figure 5-1 and 5-2 show that the FE model formulated for each particle is able to accurately predict the behaviour of the angular particles over a wide range of velocities. Table 5-2 shows the low percentage differences between the FE-predicted and measured penetrations.

Table 5-2: Percentage difference between FE predicted and measured angular particle penetrations. The experimental conditions used to calibrate the two angular particle FE models are highlighted.

\begin{tabular}{ccccc}
\hline $\begin{array}{c}\text { Particle } \\
\text { Angularity }\end{array}$ & $\begin{array}{c}\text { Velocity } \\
(\mathrm{m} / \mathrm{s})\end{array}$ & $\begin{array}{c}\text { Experimental } \\
\mathbf{P}_{\mathrm{d}}(\mathrm{cm})\end{array}$ & $\begin{array}{c}\text { FE } \mathrm{Pd}_{\mathrm{d}} \\
(\mathrm{cm})\end{array}$ & $\begin{array}{c}\text { Percent } \\
\text { error }\end{array}$ \\
\hline 60 & 25 & 1.69 & 1.55 & 8.28 \\
60 & 30 & 2.37 & 2.24 & 5.49 \\
60 & 33 & 2.66 & 2.52 & 5.26 \\
$\overline{60}$ & $\overline{49}$ & $\overline{3.44}$ & $\underline{3.46}$ & $\underline{0.58}$ \\
60 & 48 & 4.36 & 4.51 & 3.44 \\
60 & 55 & 4.98 & 5.38 & 8.03 \\
45 & 35 & 1.65 & 1.82 & 10.3 \\
45 & 45 & 2.87 & 3.05 & 6.27 \\
45 & 47 & 3.22 & 3.35 & 4.04 \\
45 & 59 & 5.89 & 5.94 & 1.29 \\
45 & 55 & 4.28 & 4.11 & 3.97 \\
45 & 60 & 4.84 & 4.73 & 2.27 \\
\hline
\end{tabular}

\subsubsection{Effect of angularity on penetration depth}

The effect of angularity on penetration can be examined by looking at the penetrations of particles having the same mass and velocity (hence, incident energy), differing only in their angularity. 
The three cases to compare are the $6.0 \mathrm{~mm} 60^{\circ}$ steel angular particle, a $5.64 \mathrm{~mm} 45^{\circ}$ steel angular particle, and a $2.78 \mathrm{~mm}$ radius sphere, each having an incident velocity of $40 \mathrm{~m} / \mathrm{s}$. Although a $5.63 \mathrm{~mm}$ $45^{\circ}$ steel angular particle and a $2.78 \mathrm{~mm}$ radius sphere were not tested in the present study, results from the $5.83 \mathrm{~mm} 45^{\circ}$ steel angular particle and a $1.59 \mathrm{~mm}$ radius sphere may be scaled using the eighth pi group in order to obtain estimates of their penetrations. The steps are as follows: from the linear fit given by the equation $P_{d}=0.1306 \mathrm{v}-2.9022$, the penetration of the $5.83 \mathrm{~mm} 45^{\circ}$ steel angular particle is found to be $2.31 \mathrm{~cm}$. Using the eighth pi group, this penetration can be scaled to obtain an equivalent penetration for a $5.64 \mathrm{~mm} 45^{\circ}$ steel angular particle. A similar procedure can be used to extrapolate the penetration of a $2.78 \mathrm{~mm}$ radius sphere from the data shown in Figure $4-2$ for a $3.18 \mathrm{~mm}$ diameter steel sphere. The impact results for these three particles with an initial velocity of $40 \mathrm{~m} / \mathrm{s}$ are presented in Table 5-3. From these results, it is apparent that penetration increases with angularity and decreases with impact area, defined as the area projected by the particle on the target throughout the penetration (Table 5-3 lists the maximum impact/projected area). It should be noted that the Pi groups developed for the spheres would be the same as those developed for angular particles, the only restriction being that, for two particles to be compared, they must have the same angularity.

Table 5-3: Effect of angularity on particle penetration for particle having the same kinetic energy.

\begin{tabular}{ccccc}
\hline $\begin{array}{c}\text { Particle } \\
\text { Angularity }\end{array}$ & Mass (g) & $\begin{array}{c}\text { Impact Area } \\
\left(\mathrm{mm}^{2}\right)\end{array}$ & $\begin{array}{c}\text { Velocity } \\
(\mathrm{m} / \mathrm{s})\end{array}$ & $\mathbf{P}_{\mathrm{d}}(\mathrm{cm})$ \\
\hline 60 & 0.7027 & 18.29 & 40 & 3.44 \\
45 & 0.7027 & 23.93 & 40 & 2.23 \\
Sphere & 0.7027 & 24.28 & 40 & 2.77 \\
\hline
\end{tabular}




\subsubsection{Implications of the study of angularity on penetration depth}

The study of angular particles on penetration depth has shown that angular particles with a similar kinetic energy and smaller projected area will penetrate deeper with respect to their spherical counterparts. This would suggest the use of angular particles in cases where the particle size, density or impact velocity may be too low to ensure adequate penetration to the viable epidermis. This brief examination of the normal impact of angular particles may be expanded to study more realistic experimental conditions in which the particle may not be oriented normal to the surface. In addition, the angular particle shape may be altered to better imitate the irregular shapes often produced through the manufacture of pharmaceuticals. 


\section{Chapter 6. Conclusions and Recommendations for Future Work}

\subsection{Summary of Major Conclusions and Contributions}

This thesis represents, to the author's knowledge, the first investigation utilizing an FE model in conjunction with scaled up experiments in order to study pharmaceutical particle impact with skin for the purposes of pharmaceutical drug delivery. A number of important contributions have been made. These are outlined below.

A finite element model of the impact of a single powder drug particle with skin has been developed that establishes a relationship between the initial particle parameters of velocity, density, size and shape and its final penetration. The effect of varying one of the parameters within the model can easily be determined without having to perform difficult tests on skin. Furthermore, use of the model allowed estimation of material parameters that were able to accurately predict the response of skin in a variety of loading conditions. The scaled elastic modulus of $2.25 \mathrm{MPa}$ (Section 4.2.1) from the high-strain infinitesimal shear modulus value was also in agreement values those found in the literature.

The use of dimensional analysis in the context of this project has also been unique and valuable. The scaling relations were helpful in the selection of an appropriate skin simulant to be used in the larger-scale experiments. They were also used in the determination of an appropriate infinitesimal shear modulus for skin through the relation of equivalent penetration produced by the two systems. In addition, they were also used in order to relate and compare the experimental results on the gelatin to those from skin, enabling a proper comparison between the two systems.

Although gelatin has been sparsely used as a simulant in the study of skin, it has never, to the author's knowledge, been used for the purpose of scaled up experimentation. Its transparency, 
controllable dimensions, and the ease with which the mechanical properties can be altered through manipulation of gelatin weight percent in the formulation make it an ideal testing medium for the purposes of this study. Its appropriateness as a skin simulant was tested using balls of varying size, density and velocity and was found to produce the same trends documented for skin. Furthermore, upon establishing its appropriateness as a skin simulant, it was possible to examine the effect of impact conditions on penetration in ways not covered within the literature. An example of this was the testing of particles having different angularities.

The effect of particle angularity has never before been examined in the context of pharmaceutical transdermal injection. It is a great departure from the spherical particle assumption utilized in all previous epidermal powder injection studies. In the present work, it was found that the penetration depth increases with angularity. This is an important result since typical powdered drug particles are granular, rather than spherical. The present results have demonstrated the feasibility of using particle angularity in in addition to size, density and velocity, in order to optimize the process and properly target the epidermal region of interest.

\subsection{Implications for the Epidermal Powder Injection Industry}

Powder injection has been developed with a unique set of characteristics, able to avoid common problems associated with leading methods of transdermal drug delivery. It has also been found to elicit much stronger and quicker immune responses upon administration. However, widespread success has been limited by problems such as the proper manufacture of solid particles, the eradication of pain and bruising, and variability in velocity profile and spatial distribution. All of these matters are further complicated by a lack of ability to properly determine how performance may be impacted by a change in the particle's characteristics. This thesis has estabilished a novel methodology that can be used to 
conduct detailed investigations to optimize the performance, using a a finite element model of skin linked to scaled-up experiments on a skin simulant.

The main advantage of utilizing the FE model is that the effects of changes in the process parameters can be rapidly and easily determined. Single particle impacts produced by the FE model have been shown to reproduce results found in the literature accurately and represents the average of many data points. Furthermore, parametric studies are easier to complete; the effect of one particular parameter such as density or velocity can be isolated and distinguished. Conversely, in studies involving the skin, particles are often found in a range of sizes, densities, and velocities whose effects cannot be separated and related to the variations found in the penetration results.

\subsection{Limitations of the Model}

The limitations of the model presented in this thesis can be summarized as follows:

- The single-layered homogeneous isotropic model is not able to capture the complex and dynamic features of the skin such as its state of pretension in vivo, direction-dependent properties, viscoelastic effects and the differences in properties between the primary layers involved in epidermal powder injection. Nevertheless, the model developed in this study serves as a good platform for further development and has been shown to provide penetration estimates in good agreement with experimentally-obtained values found in the literature.

- It is difficult to select a skin simulant that is able to satisfy all non-dimensional requirements as specified by the scaling relations. Yet, satisfaction of Pi groups carrying the most significance has been shown to result in a two systems that can closely mimic each other with relatively little error. 
- The calibrated model reflects only one set of test conditions, i.e., one set of temperature, relative humidity, and stratum corneum thickness.

\subsection{Recommendations for Future Work}

This work was focussed on developing a much needed connection between the initial drug particle parameters and the resulting penetration into skin. The work could be extended as follows:

- Completing the study of angular particles including a more detailed parametric analysis of the effect of angularity, size and orientation on final penetration depth .

- Confirm gelatin as a suitable skin simulant for the impact of angular particles by testing particles of different angularity on skin (data not available in the literature).

- Implementing a more realistic particle shape into the finite element model.

- Developing a method similar to the one detailed in this study utilizing a two layered model, characterizing each layer with appropriate material parameters.

- Creating a more realistic FE model of skin including anisotropy, viscoelasticity, an initial state of pre-tension, and multiple failure criteria based on particle size. 


\section{References}

[1] Partidos CD. Delivering vaccines into the skin without needles and syringes. Expert Review of Vaccines. 2003;2(6):753-61.

[2] Giudice EL, Campbell JD. Needle-free vaccine delivery. Advanced Drug Delivery Reviews. 2006;58(1):68-89.

[3] Prausnitz MR, Mitragotri S, Langer R. Current status and future potential of transdermal drug delivery. Nature Reviews Drug Discovery. 2004;3(2):115-24.

[4] Tanner T, Marks R. Delivering drugs by the transdermal route: Review and comment. Skin Research and Technology. 2008;14(3):249-60.

[5] Prausnitz MR. Microneedles for transdermal drug delivery. Advanced Drug Delivery Reviews. 2004;56(5):581-7.

[6] Arora A, Prausnitz MR, Mitragotri S. Micro-scale devices for transdermal drug delivery. International Journal of Pharmaceutics. 2008;364(2):227-36.

[7] Baxter J, Mitragotri S. Needle-free liquid jet injections: Mechanisms and applications. Expert Review of Medical Devices. 2006;3(5):565-74.

[8] Degim IT. New tools and approaches for predicting skin permeability. Drug Discovery Today. 2006;11(11-12):517-23.

[9] Morimoto T, Itoh T. Thermoregulation and body fluid osmolality. Journal of Basic and Clinical Physiology and Pharmacology. 1998;9(1):51-72.

[10] Benzinger TH. Heat regulation: homeostasis of central temperature in man. Physiological Reviews. 1969;49(4):671-759.

[11] Fore J. A review of skin and the effects of aging on skin structure and function. Ostomy Wound Management. 2006;52(9):24-37.

[12] Wysocki AB. Skin anatomy, physiology, and pathophysiology. Nursing Clinics of North America. 1999;34(4):777-97.

[13] Dubertret L. Skin and environment. Peau et environnement. 2000;323(7):629-32.

[14] Dean HJ, Fuller D, Osorio JE. Powder and particle-mediated approaches for delivery of DNA and protein vaccines into the epidermis. Comparative Immunology, Microbiology and Infectious Diseases. 2003;26(5-6):373-88.

[15] Lee AJ, King JR, Rogers TG. A multiple-pathway model for the diffusion of drugs in skin. IMA Journal of Mathemathics Applied in Medicine and Biology. 1996;13(2):12750. 
[16] Landmann L. The epidermal permeability barrier. Anatomy and Embryology. 1988;178(1):1-13.

[17] Briggaman RA. Epidermal-dermal interactions in adult skin. Journal of Investigative Dermatology. 1982;79(Suppl. 1).

[18] Standring S, ed. Gray's Anatomy: The Anatomical Basis of Medicine and Surgery. 39th ed. UK: Churchill-Livingstone 2004.

[19] Barbero AM, Frasch HF. Modeling of diffusion with partitioning in stratum corneum using a finite element model. Annals of Biomedical Engineering. 2005;33(9):128192.

[20] Mitragotri S. Breaking the skin barrier. Advanced Drug Dellvery Reviews. 2004;56(5):555-6.

[21] Holbrook KA, Odland GF. Regional differences in the thickness (cell layers) of the human stratum corneum: an ultrastructural analysis. Journal of Investigative Dermatology. 1974;62(4):415-22.

[22] Castiel-Higounenc I, Chopart M, Ferraris C. Stratum corncum lipids: Specificity, role, deficiencies and modulation. OCL - Oleagineux Corps Gras Lipides. 2004;11(6):401-6.

[23] Schurer NY, Plewig G, Elias PM. Stratum corneum lipid function. Dermatologica. 1991;183(2):77-94.

[24] Kendall M, Mitchell T, Wrighton-Smith P. Intradermal ballistic delivery of microparticles into excised human skin for pharmaceutical applications. Journal of Biomechanics. 2004;37(11):1733-41.

[25] Stachowiak JC, Li TH, Arora A, Mitragotri S, Fletcher DA. Dynamic control of needle-free jet injection. Journal of Controlled Release. 2009;135(2):104-12.

[26] Burkoth TL, Bellhouse BJ, Hewson G, Longridge DJ, Muddle AG, Sarphie DF. Transdermal and transmucosal powdered drug delivery. Critical Reviews in Therapeutic Drug Carrier Systems. 1999;16(4):331-84.

[27] Hardy MP, Kendall MAF. Mucosal deformation from an impinging transonic gas jet and the ballistic impact of microparticles. Physies in Medicine and Biology. 2005;50(19):4567-80.

[28] Ziegler AS, Schluecker E, Reichet-Lennianski P, Alt N, Lee G. Inactivation effects on proteins in a needle-free vaccine injector. Engineering in Life Sciences. 2006;6(4):38493.

[29] Ziegler AS. Needle-free delivery of powdered protein vaccines: A new and rapidly developing technique. Journal of Pharmaceutical Innovation. 2008;3(3):204-13. 
[30] Liu Y, Costigan G. CFD design and characterization of a supersonic conle nozzle for powdered vaccine/drug delivery system. Collection of Technical Papers - AIAA Applled Aerodynamics Conference; 2006; San Francisco, CA; 2006. p. 2047-55.

[31] Chen D, Maa YF, Haynes JR. Needle-free epidermal powder immunization. Expert Review of Vaccines. 2002;1(3):265-76.

[32] Wolf AR, Stoddart PA, Murphy PJ, Sasada M. Rapid skin anaesthesla using hlgh velocity lignocaine particles: A prospective placebo controlled trial. Archives of Disease in Childhood. 2002;86(4):309-12.

[33] Mitchell TJ, Kendall MAF, Bellhouse BJ. A ballistic study of mlcro-partlcle penetration to the oral mucosa. International Journal of Impact Engineering. $2003 ; 28(6): 581-99$.

[34] Diridollou S, Black D, Lagarde JM, Gall Y, Berson M, Vabre V. Sex- and sitedependent variations in the thickness and mechanical properties of human skin in vivo. International Journal of Cosmetic Science. 2000;22(6):421-35.

[35] Doubal S, Klemera P. Changes in mechanical properties of skin as a marker of biological age. Sbornik Lekarsky. 1998;99(4):423-8.

[36] Dehn J. Unified theory of penetration. International Journal of Impact Engineering. 198621 October 1986 through 24 October 1986;5(1-4):239-48.

[37] Kendall M, Rishworth S, Carter F, Mitchell $T$. Effects of relative humidity and ambient temperature on the ballistic delivery of micro-particles to excised porcine skin. Journal of Investigative Dermatology. 2004;122(3):739-46.

[38] Hendriks FM, Brokken D, van Eemeren JTWM, Oomens CWJ, Baaijens FPT, Horsten JBAM. A numerical-experimental method to characterize the non-linear mechanical behavior of human skin. Skin Research and Technology, 2003;9(3):274-83.

[39] Lahm K, Lee G. Penetration of crystalline powder particles into excised human skin membranes and model gels from a supersonic powder injector. Journal of Pharmaceutical Sciences. 2006;95(7):1511-26.

[40] Jauhari M, Mahanta P. Wound ballistics: study of the rupture of human skin membrane under the immpact of a projectile. Defence Science Journal. 1979;29(3):101-6.

[41] Jussila J, Leppaniemi A, Paronen M, Kulomaki E. Ballistic skin simulant. Forensie Science International. 2005;150(1):63-71.

[42] Peters CE, Sebourn CL. Wound ballistics of unstable projectiles. Part II: Temporary cavity formation and tissue damage. Journal of Trauma - Injury, Infection and Critical Care. 1996;40(3 SuppL). 
[43] Peters CE, Sebourn CL, Crowder HL. Wound ballistics of unstable projectiles. Part I: Projectile yaw growth and retardation. Journal of Trauma - Injury, Infection and Critical Care. 1996;40(3 Suppl.).

[44] DiMaio VJM. Penetration and perforation of skin by bullets and missiles. A review of the literature. American Journal of Forensic Medicine and Pathology. 1981;2(2):107-10.

[45] Yoganandan N, Pintar FA. Biomechanics of penetrating trauma. Critical Reviews in Biomedical Engineering. 1997;25(6):485-501.

[46] Shergold OA, Fleck NA. Mechanisms of deep penetration of soft solids, with application to the injection and wounding of skin. Proceedings of the Royal Society A: Mathematical, Physical and Engineering Sciences. 2004;460(2050):3037-58.

[47] - Shergold OA, Fleck NA, King TS. The penetration of a soft solid by a liquid jet, with application to the administration of a needle-free injection. Journal of Biomechanics. 2006;39(14):2593-602.

[48] Schramm-Baxter J, Katrencik J, Mitragotri S. Jet injection into polyacrylamide gels: Investigation of jet injection mechanics. Journal of Biomechanics. 2004;37(8):1181-8.

[49] Graeber GM; Belville WD, Sepulveda RA. A safe model for creating blunt and penetrating ballistic injury. Journal of Trauma. 1981;21(6):473-6.

[50] Ionescu I, Guilkey J, Berzins M, Kirby RM, Weiss J. Computational simulation of penetrating trauma in biological soft tissues using the material point method. Studies in health technology and informatics. 2005;111:213-8.

[51] Khatyr F, Imberdis C, Vescovo P, Varchon D, Lagarde JM. Model of the viscoelastic behaviour of skin in vivo and study of anisotropy. Skin Research and Technology. 2004;10(2):96-103.

[52] Retel V, Vescovo P, Jacquet E, Trivaudey F, Varchon D, Burtheret A. Nonlinear model of skin mechanical behaviour analysis with finite element method. Skin Research and Technology. 2001;7(3):152-8.

[53] Wan Abas WAB. Biaxial tension test of human skin in vivo. Biomedical Materials and Engineering. 1994;4(7):473-86.

[54] Pailler-Mattaei C, Zahouani $\mathbf{H}$. Study of adhesion forces and mechanical properties of human skin in vivo. Journal of Adhesion Science and Technology. 2004;18(15-16):173958.

[55] Zhang M, Turner-Smith AR, Roberts VC. Reaction of skin and soft tissue to shear forces applied externally to the skin surface. Proceedings of the Institution of Mechanical Engineers, Part H: Journal of Engineering in Medicine. 1994;208(4):217-22. 
[56] Bosboom EMH, Hesselink MKC, Oomens CWJ, Bouten CVC, Drost MR, Baaijens FPT. Passive transverse mechanical properties of skeletal muscle under in vivo compression. Journal of Biomechanics. 2001;34(10):1365-8.

[57] Oomens CWJ, van Campen DH, Grootenboer HJ. A mixture approach to the mechanics of skin. Journal of Biomechanics. 1987;20(9):877-85.

[58] Kendall MAF, Chong YF, Cock A. The mechanical properties of the skin epidermis in relation to targeted gene and drug delivery. Biomaterials. 2007;28(33):4968-77.

[59] Bader DL, Bowker P. Mechanical characteristics of skin and underlying tissues in vivo. Biomaterials. $1983 ; 4(4): 305-8$.

[60] Agache PG, Monneur C, Leveque JL, De Rigal J. Mechanical properties and Young's modulus of human skin in vivo. Archives of Dermatological Research. 1980;269(3):221-32.

[61] Diridollou S, Patat F, Gens F, Vaillant L, Black D, Lagarde JM. In vivo model of the mechanical properties of the human skin under suction. Skin Research and Technology. 2000;6(4):214-21.

[62] Hendriks FM, Brokken D, Oomens CWJ, Baaijens FPT. Influence of hydration and experimental length scale on the mechanical response of human skin in vivo, using optical coherence tomography. Skin Research and Technology. 2004;10(4):231-41.

[63] Shergold OA, Fleck NA, Radford D. The uniaxial stress versus strain response of pig skin and silicone rubber at low and high strain rates. International Journal of Impact Engineering. 2006;32(9):1384-402.

[64] Wildnauer RH, Bothwell JW, Douglass AB. Stratum corneum biomechanical properties. I. Influence of relative humidity on normal and extracted human stratum corneum. Journal of Investigative Dermatology. 1971;56(1):72-8.

[65] Daly CH. Biomechanical properties of dermis. Journal of Investigative Dermatology. 1982;79(Suppl. 1).

[66] Lanir Y, Fung YC. Two dimensional mechanical properties of rabbit skin. II. Experimental results. Journal of Biomechanics. 1974;7(2):171-82.

[67] Payne PA. Measurement of properties and function of skin. Clinical Physics and Physiological Measurement. 1991;12(2):105-29.

[68] Wilkes GL, Brown IA, Wildnauer RH. The biomechanical properties of skin. CRC critical reviews in bioengineering. 1973;1(4):453-95.

[69] Haut RC, Little RW. A constitutive equation for collagen fibers. Journal of Biomechanics. 1972;5(5). 
[70] Bischoff JE, Arruda EM, Grosh K. Finite element modeling of human skin using an isotropic, nonlinear elastic constitutive model. Journal of Biomechanics. 2000;33(6):645-52.

[71] Fung YCB. Biorheology of soft tissues. Biorheology. 1973;10(2):139-55.

[72] Tong P, Fung YC. The stress strain relationship for the skin. Journal of Biomechanics. 1976;9(10):649-57.

[73] Barbanel JC. Time dependent mechanical properties of skin. Glasgow: University of Strathclyde; 1979.

[74] Wijn PFF. The alinear viscoelastic properties of human skin in vivo for small deformations: University of Nijmegen; 1980.

[75] Kauer M, Vuskovic V, Dual J, Szekely G, Bajka M. Inverse finite element characterization of soft tissues. Medical Image Analysis. 2002;6(3):275-87.

[76] Delalleau A, Josse G, Lagarde JM, Zahouani H, Bergheau JM. Characterization of the mechanical properties of skin by inverse analysis combined with the indentation test. Journal of Biomechanics. 2006;39(9):1603-10.

[77] Flynn C, McCormack BAO. Finite element modelling of forearm skin wrinkling. Skin Research and Technology. 2008;14(3):261-9.

[78] Larrabee Jr WF, Galt JA. A finite element model of skin deformation. III. The finite element model. The Laryngoscope. 1986;96(4):413-9.

[79] Kirby SD, Wang B, To CWS, Lampe HB. Nonlinear, three-dimensional finiteelement model of skin biomechanics. Journal of Otolaryngology. 1998;27(3):153-60.

[80] Rubin MB, Bodner SR, Binur NS. An elastic-viscoplastic model for excised facial tissues. Journal of Biomechanical Engineering. 1998;120(5):686-9.

[81] Szirtes T. Applied Dimensional Analysis and Modeling. 2nd ed. Toronto: Elsevier 2007.

[82] Pailler-Mattei C, Pavan S, Vargiolu R, Pirot F, Falson F, Zahouani H. Contribution of stratum corneum in determining bio-tribological properties of the human skin. Wear. 2007;263(7-12 SPEC. ISS.):1038-43.

[83] Yuan Y, Verma R. Measuring microelastic properties of stratum corneum. Colloids and Surfaces B: Biointerfaces. 2006;48(1):6-12.

[84] Yeoh OH. On the Ogden strain-energy function. Rubber Chemistry and Technology. 1997;70(2):175-82.

[85] Walley SM, Field JE, Greengrass M. An impact and erosion study of polyetheretherketone. Wear. 1987;114(1):59-72. 
[86] Bot A, Van Amerongen IA, Groot RD, Ilockstra NL, Agterof WVGM. Large Deformation Rheology of Gelatin Gels. Polymer Gels and Networks. 1996; $4(3): 189-227$.

[87] Moy P, Weerasooriya T, Juliano TF, VanLandingham MR, Chen W. Dynumlc response of an alternative tissue simulant, physically associallng gcls (PAG). P'roccedlings of the 2006 SEM Annual Conference and Exposition on Experimental and Applled Mechanics 2006; 2006; Saint Louis, MO; 2006. p. 304-10.

[88] Cronin DS, Salisbury CP, Horst CR. Iligh rate characterlzation of low Impedance materials using a Polymeric Split llopkinson Pressure Bar. Procecdings of tlie 2006 SEM Annual Conference and Exposition on Experimental and Applled Mechanics 2006; 2006; Saint Louis, MO; 2006. p. 314-22.

[89] Cheng ZQ, Thacker JG, Pilkey WD, Ilollowell WT, Reagan SW, Sleveka UM. Experiences in reverse-engineering of a finite element automobile crash model. Finlte Elements in Analysis and Design. 2001;37(11):843-60.

[90] Ankersen J. Puncture resistance and tensile strength of skin slmulants. Procecdlings of the Institution of Mechanical Engineers, Part 11: Journal of Enginecring in Medicinc. 1999;213(6):493-501.

[91] Jacquemoud C, Bruyere-Garnier K, Coret M. Methodology to determine fallure characteristics of planar soft tissues using a dynamic tensile test. Journal of Iblomechanics. 2007;40(2):468-75.

[92] Snedeker JG, Niederer P, Schmidlin FR, Farshad M, Demetropoulos CK, Lee J1, ct al. Strain-rate dependent material properties of the porcine and human kldney capsule. Journal of Biomechanics. 2005;38(5):1011-21.

[93] Takaffoli M, Papini M. Finite element analysis of single impacts of angular particles on ductile targets. Wear. 2009;267(1-4):144-51.

[94] Escoffier C, De Rigal J, Rochefort A, Vasselet R, Leveque JL, Agache PG. Agerelated mechanical properties of human skin: An in vivo study. Journal of Investigative Dermatology. 1989;93(3):353-7. 